\title{
LA CALIDAD INSTITUCIONAL EN ARGENTINA EN EL LARGO PLAZO*
}

\author{
MARÍA FLORENCIA ARAOZ \\ Universidad del Norte Santo Tomás de Aquino ${ }^{\mathrm{a}}$
}

Institutional quality in Argentina in the long run

\begin{abstract}
This paper presents a multidimensional indicator of institutional quality in Argentina for the period 1862-2008. Initially, it describes a set of variables that aim to measure issues related to the legal framework prevailing in Argentina and its implementation, such as changes in the Constitution and the provincial Constitutions, declarations of state of siege and federal interventions, freedom of press, central bank independence. The indicator is then constructed through the principal component analysis.

The results suggest that periods of high institutional quality in Argentina coincided with the most expansion and relative progress. In other words, poor institutional quality would not only be reflected in lower growth rates but also compromises the ability to follow those countries with the best performace.
\end{abstract}

Keywords: Institutions, Indicators, Argentine

JEL Classification: E02, C43, O17

* Received 20 January 2012. Accepted 31 October 2012. Este artículo forma parte de mi tesis de maestría en la Universidad Nacional de Tucumán. Mi agradecimiento a su directora, Ana María Cerro, y a Esteban Nicolini por sus invaluables observaciones y sugerencias. Agradezco también los comentarios recibidos en la XLIV Reunión Anual de la Asociación Argentina de Economía Política y en las XXII Jornadas de Historia Económica de la Asociación Argentina de Historia Económica, así como los de los referees y editores de esta revista. A la UNSTA por brindarme un espacio para realizar mis investigaciones, al Consejo de Investigaciones de la Universidad Nacional de Tucumán y a Federico, Ignacio y Florencia por su constante apoyo y colaboración

a Centro de Investigaciones Económicas para el Desarrollo Humano (CIEDH), Facultad de Economía y Administración de la Universidad del Norte Santo Tomás de Aquino (UNSTA). Dirección postal: 9 de Julio 165, 5 piso, San Miguel de Tucumán, Tucumán, Argentina (T4000IHC). Correo-e: faraoz@unsta.edu.ar. 


\section{RESUMEN}

Este artículo presenta un indicador multidimensional de calidad institucional para Argentina durante el período 1862-2008. Inicialmente, se describe un conjunto de variables que miden cuestiones de jure y de facto, tales como cambios en la Constitución nacional y en las Constituciones provinciales, declaraciones de estado de sitio, intervenciones federales, libertad de prensa, independencia del banco central. Luego, el indicador se construye a través del análisis de componentes principales.

Los resultados sugieren que los períodos de alta calidad institucional en Argentina coincidieron con los de mayor expansión y avance relativo. En otras palabras, la mala calidad institucional no solo se habría reflejado en tasas de crecimiento bajas sino en una menor capacidad de seguir a los países de mejor desempeño.

Palabras clave: Instituciones, Indicadores, Argentina

«The institutions needed by a country are no independent of that country's history» Dani Rodrik (2007, p. 159)

\section{INTRODUCCIÓN}

La evolución de la economía argentina en el período 1862-2008 ha sido, cuando menos, desconcertante. Hasta 1930 creció a un ritmo con pocos paralelos en la historia económica, llegó a ubicarse entre los países de mayor nivel de ingreso per cápita y se encontró entre los 10 más ricos del mundo. Cortés Conde (2005) señala que el período 1880-1914 fue testigo del mayor y más largo crecimiento en la historia argentina, durante el cual la actividad económica se expandió sostenidamente a una tasa promedio de alrededor del 6\%. «Todo hace creer que la República Argentina está llamada a rivalizar en su día con los Estados Unidos de la América del Norte», se escribió allá por $1919^{1}$. Sin embargo, cien años después el panorama dista de aquel predicho a comienzos de siglo XX y ciertamente Argentina es un caso de estudio que llama la atención debido a su decepcionante desempeño.

La literatura ha señalado, tradicionalmente, el progreso tecnológico y la acumulación de capital físico y humano como motores del crecimiento y de la prosperidad económica en el largo plazo. Sin embargo, Hofman (2001), Acemoglu y Robinson (2008) y Rodrik (2007), entre otros, sostienen que

\footnotetext{
${ }^{1}$ Citado en Gerchunoff y Llach (2005, p. 459).
} 
estos factores son apenas causas próximas, posibles de identificar y cuantificar a través de la contabilidad del crecimiento, pero que no explican por qué algunos países son más ricos ni por qué crecen más. Para responder estos interrogantes, señalan los autores, deberían explorarse las llamadas causas últimas o fundamentales, entre las que destacan las instituciones. De hecho, Acemoglu y Robinson (2008) afirman que estas son el principal determinante de las diferencias de desarrollo entre los países. En tanto que Rodrik (2007, p. 51 y p. 184) sostiene que «la calidad institucional es la clave de las pautas de prosperidad prevaleciente en todo el mundo», y que "en el largo plazo, la cuestión principal que asegura convergencia con el nivel de vida de los países avanzados es la adquisición de instituciones de alta calidad ${ }^{2}$.

En esta línea, buscando dar respuestas al por qué del decepcionante comportamiento de la economía argentina, Cortés Conde (1997), Taylor (1994) y Della Paolera y Taylor (1998), entre otros, destacan el papel negativo de las políticas económicas inadecuadas. En tanto que Cortés Conde (1998, pp. 7-9) afirma que «para analizar el problema de la Argentina no debemos preguntarnos si la economía fue exitosa, sino si tuvo las instituciones adecuadas para que pudiera serlo». Sturzenegger (2003), por otra parte, sostiene que la debilidad institucional fue un rasgo característico de la historia argentina desde comienzos del siglo XIX y una de las causas del proceso de declinación que se inicia, según este autor, en 1930. Mientras Llach (1987) señala que la falta de consenso social y de una estructura de contratos creíbles habría llevado a Argentina a convertirse en un caso extremo de inestabilidad política.

Estas hipótesis no se contraponen entre sí y, de hecho, podrían ser alineadas dentro de la propuesta de Acemoglu et al. (2003), quienes sostienen que las políticas distorsivas son síntomas y no causas de una mala performance; es decir, que las sociedades persiguen políticas macroeconómicas distorsivas porque tienen o han tenido instituciones débiles ${ }^{3}$.

En definitiva, los autores que mencionan al contexto institucional como determinante del desempeño de la economía argentina no son pocos. Sin embargo, esta perspectiva ha sido escasamente abordada de manera empírica en el largo plazo, cuestión que no sorprende cuando se toma en cuenta la escasa disponibilidad de datos relacionados con la calidad de las instituciones que abarquen períodos de tiempo prolongados.

Dos excepciones son los trabajos de Sanz Villarroya (2009) y Prados de la Escosura y Sanz Villarroya (2009) ${ }^{4}$. En el primer caso, buscando evaluar el papel que jugaron las instituciones en el retraso relativo de Argentina -en relación a Australia y Canadá- la autora construye un Índice Reducido de

\footnotetext{
2 Traducciones del autor.

3 «Distortionary macroeconomic policies are not typically chosen because politicians believe that high inflation or overvalued exchange rates are good for economic performance. Instead, they reflect underlying institutional problems in these countries». Acemoglu et al. (2003, p. 50).

4 En adelante, Sanz (2009) y Prados y Sanz (2009).
} 
Libertad Económica (IRLE) que resume los resultados de las principales políticas aplicadas en Argentina durante el período 1875-20005. El IRLE involucra variables tales como el tamaño relativo del consumo público en relación con el consumo total, la tasa de depreciación real del dinero, el nivel de protección nominal y la diferencia entre el tipo de cambio oficial y el de mercado.

Prados y Sanz (2009), por otro lado, construyen un indicador del nivel de cumplimiento de los contratos basado en la proporción de depósitos en el sistema bancario respecto a la oferta monetaria - CIM por sus siglas en inglés, contract intensive money o "dinero intensivo en contratos»-. Los autores buscan a través de este indicador analizar en qué medida la estructura de incentivos derivada de los derechos de propiedad vigentes en Argentina durante el período 1863-2003 condicionó su proceso de acumulación de capital y, por tanto, de crecimiento ${ }^{6}$.

Aunque, probablemente, estos sean algunos de los primeros trabajos de este tipo para Argentina, la medición de calidad institucional que realizan es limitada, puesto que, de acuerdo a lo señalado por Glaeser et al. (2004) este tipo de indicadores deberían capturar reglas que impongan restricciones al comportamiento humano, y no resultados de políticas.

En este artículo se construye un índice de calidad institucional para Argentina que comprende el período $1862-2008^{7}$. En su definición se procura abarcar dimensiones que van más allá de las meras políticas o económicas, incluyendo variables relacionadas con el respeto por los derechos de propiedad - tales como cambios en la Constitución nacional y en las Constituciones provinciales-, variables relacionadas con la estabilidad del sistema político -medidas a través de las interrupciones del orden democrático, declaraciones de estado de sitio e intervenciones federales- y variables

5 «... the macroeconomic policies implemented by a government constitute an important part of the institutional framework since they provide the rules of the game which have to be obeyed by economic agents as they invest, produce and consume». Sanz Villarroya (2009, p. 320).

${ }^{6}$ El razonamiento que subyace tras el indicador CIM es el siguiente: cuando los agentes económicos consideran que operan en un contexto estable, en el que los derechos de propiedad no van a sufrir modificaciones drásticas y donde el cumplimiento de los contratos está asegurado, la decisión de mantener su dinero en depósitos no resulta arriesgada y, en consecuencia, su preferencia por circulante disminuiría. En ese caso, la proporción de los depósitos sobre la oferta monetaria debería de ser alta. A su vez, unos elevados porcentajes de depósitos podrían traducirse en mayores tasas de inversión y, consecuentemente, en tasas superiores de crecimiento. La situación contraria se daría cuando los agentes económicos no percibiesen la suficiente confianza del contexto en el que se desenvuelven (Prados y Sanz, 2009).

7 La elección del año 1862 como punto de partida no es casual, pues, en general, se considera que es a partir de ese momento cuando Argentina comienza a ser una nación unificada y organizada. Si bien este país declaró su independencia en 1816, recién en 1853, bajo la administración de Urquiza, sanciona de manera exitosa su primera Constitución nacional. Sin embargo, por ese entonces el país se encontraba separado en dos bloques: la Confederación y Buenos Aires. En 1862 bajo la presidencia de Mitre y con Buenos Aires reincorporada, la unidad nacional quedó consumada. 
vinculadas con el funcionamiento de la economía, tales como presupuesto, independencia del banco central o coparticipación de impuestos.

Los resultados obtenidos sugieren que en Argentina los períodos de alta calidad institucional coincidieron con los de elevado crecimiento. En tanto que los de baja calidad institucional lo hicieron con los de retraso relativo. En otras palabras, pareciera que la mala calidad institucional en Argentina no se habría reflejado en bajas tasas de crecimiento per se, sino en una menor capacidad de seguir a los países de mejor desempeño.

El trabajo se organiza del siguiente modo: en el apartado 2 se realiza una breve revisión de la literatura relacionada con instituciones, su concepto y determinantes. También se hace mención a la situación actual en torno a la construcción de indicadores institucionales. El apartado 3 describe las variables que forman el índice, discute la metodología utilizada para su construcción y analiza el comportamiento del indicador obtenido en relación con la evolución económica de Argentina. El apartado 4 finaliza con algunas conclusiones.

\section{ANTECEDENTES}

La cantidad disponible de indicadores que miden calidad institucional ha crecido exponencialmente en las últimas décadas, y sus aportes son evidentes si tenemos en cuenta que fueron de gran utilidad para demostrar la existencia de correlaciones positivas entre instituciones y crecimiento económico, contribuyendo a llamar la atención sobre su importancia en el desarrollo.

En general, los indicadores existentes expresan la posición relativa en la que se sitúan las instituciones de diversas economías, ya sea respecto a una medida ideal, entre países o bien respecto a una situación comparable en diferentes momentos de tiempo; $y$, si bien poseen la ventaja de que se calculan para un gran número de países - permitiendo realizar estudios comparativos-, tienen la desventaja de que se calculan para períodos de tiempo relativamente breves, por lo que resultan de escasa utilidad para efectuar análisis de largo plazo.

Los indicadores estimados por el proyecto Polity IV de la Universidad de Maryland son una excepción, pues contienen información anual para 164 países durante el período 1800-2010. Sin embargo, puesto que en su construcción se consideran aspectos relacionados únicamente con el régimen político y las características de reclutamiento y facultades del poder ejecutivo, consideramos que constituyen una medida limitada para evaluar calidad institucional ${ }^{8}$.

${ }^{8}$ La base de datos del proyecto Polity IV incluye indicadores anuales compuestos de democracias y autocracias institucionalizadas -DEMOC y AUTOC, respectivamente-, durabilidad de los regímenes políticos —DURABLE y PERSIST - y dos índices compuestos que surgen de combinar DEMOC y AUTOC - POLITY y POLITY 2-. Este último procedimiento permite obtener indicadores cuya escala varía entre $-10 y+10$. En un extremo, +10 , se presentan las democracias más abiertas y competitivas desde el punto de vista político. En el otro, -10 , se encuentran las 
Respecto a las fuentes de datos a partir de las cuales se calculan los índices de instituciones, en general son de dos tipos: encuestas de opinión y dictámenes de expertos que realizan comparaciones a partir de un estándar de referencia. De manera que los indicadores de calidad institucional más difundidos hoy en día se encuentran basados en percepciones, haciendo que las expectativas, los diversos grados de información o la falta de acuerdo sobre lo que se mide, sean factores que podrían impactar en las mediciones. En consecuencia, señalan Arndt y Oman (2006), lo que por un lado permite sortear problemas relacionados con la disponibilidad de información, también hace que los resultados que se obtengan no siempre puedan ser replicados, situación que afecta a su confiabilidad.

Algunos indicadores se construyen a partir de la combinación de mediciones ya existentes, tales como los estimados por el Banco Mundial. Este organismo estima seis dimensiones de gobernabilidad a través del proyecto Worldwide Governance Indicators (WGI), en donde cada dimensión resume información proveniente de índices y ránkings elaborados por otras entidades?.

Quizás, el mensaje más importante detrás de este crecimiento y esta proliferación de indicadores de calidad institucional es que no existe una manera única y definitiva de medirla, por lo que un buen punto de partida antes de abordar esta ambiciosa tarea será clarificar el concepto de instituciones, $\mathrm{y}$ en consecuencia, de calidad institucional ${ }^{10}$.

\section{1. ¿Qué entendemos por «instituciones»? Concepto e importancia}

Según Douglas North (1990, pp. 3-7), «las instituciones son las reglas de juego en una sociedad o, más formalmente, son las limitaciones ideadas por el hombre que dan forma a la interacción humana» ${ }^{11}$. Para este autor, las instituciones integran la estructura de incentivos de una sociedad y, como tales, constituyen factores determinantes del desempeño económico cuya principal función es reducir la incertidumbre.

\footnotetext{
(F'note continued)

autocracias menos abiertas y competitivas. Los indicadores se construyen en base al sistema electoral de los países, los métodos de reclutamiento en el ejecutivo y las limitaciones sobre el accionar de este último. Más detalles acerca del proyecto Polity IV pueden ser encontrados en el sitio de Internet: <http:/www.systemicpeace.org/polity/polity4.htm>.

9 Una guía bastante completa de indicadores institucionales, sus fuentes, periodicidad, metodología, cobertura y acceso puede encontrarse en el sitio de Internet <www.worldbank.org/publicsector/indicators.htm $>$. También los anexos de los informes Governance Matters, en sus diferentes versiones, procuran esta información. Véase en Internet: <http://info.worldbank.org/ governance/wgi/index.asp >

10 A lo largo de este artículo se emplean de manera indistinta los términos «instituciones»y "calidad institucional», situación frecuente en la bibliografía relacionada. Véase, por ejemplo, Kaufmann y Kray (2008, p. 3).

11 Traducción del autor.
} 
Kaufmann y Kraay (2008, pp. 1-3) señalan que, aunque aún no existe consenso en torno a una definición única de gobernabilidad y calidad institucional, la mayoría hace hincapié en la importancia de un Estado capaz, responsable ante los ciudadanos y que opere bajo el imperio de la ley.

En consecuencia, podemos pensar a las instituciones como en normas y reglas que determinan los incentivos y las limitaciones que afrontan los individuos de una sociedad, incluyendo cuestiones tan diversas como leyes, sistemas políticos y derechos de propiedad. Pueden ser económicas o políticas, formales o informales.

Rodrik (2007) distingue cinco tipos de instituciones necesarias para un desarrollo económico sostenible a largo plazo; entre ellas, señala las instituciones que protegen los derechos de propiedad y garantizan el cumplimiento de los contratos como "creadoras de mercado»; es decir, que en su ausencia los mercados no existen o funcionan mal. Pero, apunta también este autor, para que los mercados funcionen «como si fueran perfectos» hacen falta, además, instituciones regulatorias que aseguren la estabilidad macroeconómica, que promuevan la seguridad social, e instituciones para la gestión de conflictos. Todas ellas deberían adaptarse en cada país para garantizar que ciertos principios económicos fundamentales se respeten, tales como reglas predecibles, incentivos adecuados, estabilidad de precios, sostenibilidad fiscal y protección de los derechos de propiedad, a través de un sistema judicial independiente, elecciones libres y libertad de prensa, entre otros.

\subsection{Determinantes de las instituciones}

Existe abundante evidencia empírica que respalda la noción de que la presencia de instituciones que protejan los derechos de propiedad, promuevan reglas de juego estables y creíbles, y generen sistemas de incentivos adecuados, redundará positivamente sobre el nivel de ingresos de un país. Al respecto, podemos ver Acemoglu et al. (2001, 2002, 2003, 2004, 2005, 2008), La Porta et al. (1998) o Engerman y Sokoloff (2002), entre otros.

Ahora bien, ¿por qué la calidad de las instituciones difiere entre países? Si está claro que cierto tipo de instituciones promueven un buen desempeño, ¿por qué no las adoptan todos? Una corriente sostiene que las influencias históricas y geográficas podrían haber jugado un papel importante. Desde esta perspectiva, variables tales como la ubicación geográfica, las condiciones climáticas y la dotación de recursos naturales pudieron tener un impacto significativo sobre el desarrollo económico de los países ${ }^{12}$. Acemoglu et al. $(2001,2002)$ proponen que las diferencias institucionales actuales entre economías podrían deberse no tanto a la dotación inicial de recursos, sino a patrones de colonización diferentes.

${ }^{12}$ Véase Engerman y Sokoloff $(2002,2005)$. 
Otros autores se han centrado en las características del sistema político para explicar cómo influye el marco institucional en el desempeño económico de los países. Rodrik (2007) califica la democracia como una «metainstitución» necesaria para construir buenas instituciones y sostiene que las democracias participativas promueven un crecimiento de mayor calidad —en relación a los regímenes autoritarios- a través de escenarios más estables y previsibles.

La Porta et al. (1998) relacionan medidas de calidad institucional con características religiosas, etnolingüísticas y legales que muestran cómo los países que tienen mayor probabilidad de disfrutar de buenas instituciones son aquellos que poseen homogeneidad etnolingüística, tradición de derecho anglosajón y dominancia de la religión protestante. Se observa lo contrario en aquellos países con tradiciones basadas en el derecho civil francés, leyes socialistas y predominancia del catolicismo o de la religión musulmana.

La existencia de rentas también podría ser un factor determinante de la calidad de las instituciones. Según esta perspectiva, las economías con recursos naturales abundantes tienden a crecer más lentamente que las economías con recursos escasos, pues una parte importante de las rentas vinculadas a estas actividades irían directamente al gobierno, exacerbando el comportamiento de caza de rentas de los agentes públicos. Ades y Di Tella (1999) encontraron que los recursos naturales ciertamente afectan la eficiencia institucional.

No podemos dejar de mencionar que, pese a la abundancia de evidencias a favor de la hipótesis de que las instituciones son una causa fundamental del crecimiento económico a largo plazo, este enfoque ha sido criticado. En este sentido, Glaeser et al. (2004) sostienen que las medidas utilizadas para llegar a esa conclusión no suelen reflejar instituciones sino políticas o elecciones que realiza el gobernante de turno. Aunque no niegan la importancia de las instituciones, cuestionan «el consenso intelectual que sostiene que las instituciones políticas que limitan al Ejecutivo causan crecimiento económico», y presentan evidencias de dictaduras en las que, no existiendo restricciones de este tipo, se observa una amplia dispersión de tasas de crecimiento $^{13}$. La principal crítica de estos autores se dirige, pues, a la medición que se realiza de las instituciones; y señala que, en general, estos indicadores no reflejan restricciones formales sobre el comportamiento ni cumplen con el criterio de permanencia propuestos en la definición de North (1990). Además, advierten que la subjetividad con la que se construyen estas medidas hace que una mejora en sus resultados se deba, probablemente, a un aumento de los ingresos y no a una mayor calidad institucional, lo cual redundaría en un problema de endogeneidad. En esta última concepción, hay quienes argumentan que es el crecimiento el que trae consigo mejores instituciones; es decir, las buenas instituciones son una consecuencia del

${ }^{13}$ Glaeser et al., 2004, p. 272. Traducción del autor. 
desarrollo económico ${ }^{14}$. Chang (2010) va un poco más allá y afirma que las teorías que sostienen la primacía de las instituciones como causal del desarrollo no solo ignoran la influencia de este último en los cambios institucionales, sino que además no prestan suficiente atención al hecho de que la relación entre instituciones y desarrollo puede variar a través del tiempo.

En general, la literatura revisada coincide en señalar que las diferencias institucionales explican la mayor parte de las diferencias entre el PIB per cápita de los países; sin embargo, la cuestión acerca de si las instituciones son la fuente fundamental de crecimiento económico o en qué medida son determinadas endógenamente sigue siendo un debate abierto. Przeworski (2004, p. 175) advierte que «las instituciones no son una causa más profunda que la oferta de factores o la tecnología: las instituciones, para reiterarlo, pueden determinar la oferta de factores y su uso, pero estos factores, a su vez, afectan al crecimiento y riqueza futura, cosa que influye en la evolución de las instituciones». En este marco, intentar identificar quién causa qué podría resultar inútil. «Instituciones y desarrollo son mutuamente endógenos y lo más que podemos esperar es identificar sus impactos recíprocos», finaliza Przeworski.

\section{CONSTRUYENDO UN INDICADOR INSTITUCIONAL}

En línea con lo apuntado por Kaufmann y Kraay (2008), Voigt (2009, pp. 3 y 22) señala que uno de los grandes retos para construir un buen indicador institucional es la carencia de una definición única y consensuada de instituciones. Plantea además que la medición que se realice «debe ser precisa, objetiva y tener en cuenta tanto elementos de jure como de facto».

En este trabajo se adopta la definición de instituciones propuesta por North (1990): el conjunto de reglas formales e informales que imponen restricciones al comportamiento humano. En consecuencia, el indicador construido se basa principalmente en reglas y no en resultados, puesto que combina indicadores sustentados en la legislación (de jure) con cuestiones relativas a su implementación (de facto). De este modo, se busca sortear la principal crítica de Glaeser et al. (2004) relacionada con la manera en que se miden las instituciones ${ }^{15}$.

Existen otras características deseables que debería cumplir un buen indicador para ser considerado como tal. Por ejemplo, generarse mediante un proceso transparente y replicable, que su cobertura geográfica y temporal sea amplia, o que los datos a partir de los que se construye provengan de fuentes válidas. La mayor parte de los indicadores de calidad institucional

${ }^{14}$ Véase, por ejemplo, Barro (1999).

15 «The results of this paper do not show that "institutions do not matter". That proposition is flatly contradicted by a great deal of available empirical evidence, including our own. Rather, our results suggest that the current measurement strategies have conceptual flaws, and that researchers would do better focusing on actual laws, rules, and compliance procedures that could be manipulated by a policy maker to assess what works». Glaesser et al. (2004, pp 26-27). 
que se estiman hoy en día satisfacen el requisito de cobertura geográfica, puesto que se publican para un gran conjunto de países; sin embargo, tal como se mencionó en el apartado 2, no siempre son replicables y, en general, cubren períodos de tiempo relativamente breves.

El indicador construido en este trabajo sortea estos últimos obstáculos, aunque no el de cobertura geográfica ${ }^{16}$. Sin embargo, no percibimos esta situación como una traba, puesto que su objetivo central es analizar la evolución de las instituciones en Argentina a través del tiempo y no su posición relativa respecto a la de otras economías. En definitiva, y tal como sostiene Rodrik (2007), las instituciones necesarias para un país no son independientes de su historia. $\mathrm{O}$, en otras palabras, sociedades distintas, con marcos institucionales diferentes, exigen análisis particulares.

A continuación se presenta una breve descripción de las variables utilizadas para la construcción del índice de calidad institucional, así como el criterio adoptado para su cuantificación ${ }^{17}$.

\subsection{Selección y construcción de las variables}

La selección de las variables que componen el índice fue realizada intentando respetar dos premisas de forma simultánea: capturar el mayor número posible de características relacionadas con el funcionamiento de las instituciones en Argentina y detectar aquellas cuyo comportamiento fuera de interés durante el extenso período bajo estudio. Una tarea nada sencilla cuando se analizan 146 años de historia, simplemente porque algunas variables de gran relevancia a mediados del siglo XIX —en pleno proceso de consolidación del Estado Argentino- no lo fueron cien años después. Sin embargo, dado el carácter de largo plazo del análisis realizado, el criterio adoptado consistió en incorporar aquellas cuya participación destacara durante un período prolongado de la historia argentina.

En cuanto a la metodología empleada para construir las variables, se utilizó la propuesta por Alesina et al. (1999) en la estimación de un Índice de Instituciones Presupuestarias, consistente en asignar un puntaje preestablecido a una serie de situaciones alternativas, seguido luego por la suma simple de estos valores ${ }^{18}$. De manera que, en una primera instancia se establecieron criterios de lo que podía considerarse «más/menos deseable»

16 Dado que en su construcción se involucran variables relacionadas íntimamente con la historiografía argentina, su extrapolación a otras economías no sería directa ni apropiada.

17 Por cuestiones de espacio, se omite la descripción de las fuentes consultadas para la construcción de cada una de las variables. No obstante, tanto estas como la base de datos de las variables construidas pueden ser examinadas en una versión preliminar de este artículo publicada como working paper de la Universidad Carlos III de Madrid — véase Araóz (2011).

18 Estos autores recopilaron información sobre las instituciones presupuestarias de un grupo de países latinoamericanos, estableciendo dos categorías para clasificar los procesos mediante los cuales se elabora y aprueba el presupuesto: colegiados, es decir, con participación de múltiples 
desde el punto de vista de la calidad institucional. Luego, cada respuesta alternativa recibió un puntaje variable entre cero (la situación «menos deseable») y diez (la «más deseable»). Las respuestas de un nivel intermedio, recibieron su puntaje según la cantidad de contestaciones posibles — si admitía tres respuestas, por ejemplo, podía recibir cero, cinco o diez puntos.

Esta etapa es, quizás, la más sensible del proceso, pues involucra una cierta cuota de subjetividad en la asignación de las respuestas y de sus respectivos puntajes, situación que intentó minimizarse respetando lineamientos establecidos por la literatura y la normativa legal en función del comportamiento esperado de cada variable. En los siguientes subapartados se darán más detalles al respecto.

Finalmente, como paso previo a la construcción del índice, se normalizaron las variables para minimizar el problema de sensibilidad a la escala de medición y, al mismo tiempo, hacer más sencilla la interpretación de sus puntajes. Luego, se emplearon dos metodologías alternativas para construir el índice: la sugerida por Alesina et al. (1999), ya reseñada, y el Análisis de Componentes Principales.

El Cuadro 1 resume el listado de variables que integran el Índice de Instituciones, así como el concepto que se quería medir mediante cada una de ellas. Una tercera columna asocia cada variable con alguno de los cinco tipos de instituciones propuestos por Rodrik (2007), mencionados en el apartado 2. Vale aclarar que esta asociación tiene carácter enunciativo y no taxativo, dado que algunas variables podrían vincularse con más de un tipo de instituciones. Por ejemplo, «coparticipación» o "presupuesto», en principio ligadas a mecanismos de estabilización macroeconómica, también podrían relacionarse con la protección de los derechos de propiedad, puesto que, un Estado con libertad para expropiar a sus contribuyentes es un Estado que difícilmente asegura el respeto de tales derechos.

Las variables seleccionadas permiten captar, en principio, tres dimensiones de las cinco propuestas por Rodrik, un resultado nada despreciable si tenemos en cuenta que tanto las instituciones reguladoras como las de seguridad social podrían considerarse fenómenos cuya importancia comenzó a percibirse más bien a mediados del siglo XX.

Veamos a continuación el proceso de construcción de cada una de estas variables.

\section{Cambios en la Constitución nacional (CN) y en las Constituciones de las provincias $(\mathrm{CP})$}

La CN provee el marco jurídico principal dentro del cual deberían moverse los actores institucionales en un país. Es la madre de todas las leyes

\footnotetext{
(F'note continued) actores dentro del poder ejecutivo y del poder legislativo, o jerárquicos, mediante decisiones mayormente centralizadas en el ejecutivo, particularmente en el Ministerio de Economía.
} 


\section{CUADRO 1}

VARIABLES INCORPORADAS AL INDICADOR DE CALIDAD INSTITUCIONAL

\begin{tabular}{|c|c|c|}
\hline Variables & $\begin{array}{c}\text { Concepto que se busca } \\
\text { medir }\end{array}$ & $\begin{array}{l}\text { Tipo de instituciones, } \\
\text { según la clasificación } \\
\text { de Rodrik (2007) }\end{array}$ \\
\hline $\begin{array}{l}\text { Cambios en la Constitución } \\
\text { nacional }\end{array}$ & \multirow[t]{2}{*}{ Estado de derecho } & \multirow[t]{2}{*}{ Derechos de propiedad } \\
\hline $\begin{array}{l}\text { Cambios en las Constituciones } \\
\text { provinciales }\end{array}$ & & \\
\hline Estado de sitio & \multirow[t]{3}{*}{ Estabilidad política } & \multirow[t]{5}{*}{$\begin{array}{l}\text { Gestión de conflictos/ } \\
\text { Derechos de propiedad }\end{array}$} \\
\hline Intervenciones federales & & \\
\hline Democracia & & \\
\hline Justicia & Independencia judicial & \\
\hline Libertad de prensa & Libertad de expresión & \\
\hline Coparticipación de impuestos & $\begin{array}{l}\text { Mecanismos de asigna- } \\
\text { ción y distribución de los } \\
\text { recursos }\end{array}$ & \multirow[t]{3}{*}{$\begin{array}{l}\text { Estabilización macro- } \\
\text { económica / Derechos de } \\
\text { propiedad }\end{array}$} \\
\hline Presupuesto & & \\
\hline Independencia del banco central & Solidez de la moneda & \\
\hline
\end{tabular}

Fuente: Ver texto

y establece, entre otras cosas, las facultades de quienes ejercen el poder, la forma de acceso al mismo y sus limitaciones.

Una reforma en la Constitución no es buena o mala de por sí, pero implica un cambio en las reglas del juego que podría alterar la previsibilidad con la que operan los agentes, generando inestabilidad e incertidumbre. Máxime en un país como Argentina, donde las reformas constitucionales, sobre todo las que se llevaron a cabo en el siglo XX, han estado teñidas por un manto de sospecha acerca de las intenciones que motivaron a sus impulsores.

La Constitución de la Nación Argentina fue promulgada el 25 de mayo de 1853 y jurada por la República (excepto Buenos Aires) el 9 de julio de ese mismo año. En 1860, Buenos Aires se unió a la Confederación Argentina y la Constitución sufrió su primera reforma. A partir de entonces, Argentina modificó su Carta Magna en diversas oportunidades ${ }^{19}$.

19 Años 1860, 1866, 1898, 1949, 1957, 1972 у 1994. 
Más allá de los motivos que dieron lugar a estas reformas, y en función de lo reseñado en el párrafo precedente, el criterio adoptado para cuantificar esta variable fue el siguiente: aquellos años en los que la $\mathrm{CN}$ no sufrió modificaciones y tuvo plena vigencia obtuvieron 10 puntos, los años durante los cuales se realizó una reforma de acuerdo con el mecanismo previsto en la Constitución recibieron 5 puntos, en tanto que se asignaron 0 puntos a aquellos años en los que hubo alguna suspensión o sustitución constitucional, entendiendo por tales los períodos en los que la vigencia constitucional se interrumpió o en los que la $\mathrm{CN}$ se reemplazó por normas que revistieron el carácter de tal, pese a no cumplir los requisitos establecidos en la CN para su correcta implementación ${ }^{20}$.

Las provincias argentinas también sucumbieron al «deseo/necesidad» de reformar su Constitución en diversas ocasiones y para tomar en cuenta esta situación se adoptó el siguiente criterio: cuando solo reformaron su Constitución menos del $25 \%$ de las provincias, se asignaron 7,5 puntos; cuando el porcentaje se elevó al 50\% de las provincias, se asignaron 5 puntos; cuando el $75 \%$ de las provincias modificaron sus cartas fundamentales, 2, 5 puntos; y 0 puntos cuando todas las provincias lo hicieron. Los años en los que no hubo reformas, sustituciones o suspensiones recibieron 10 puntos.

\section{Democracia}

Spiller y Tomassi (2000) señalan que cuanto mayor es la inestabilidad institucional en una economía, menor es la capacidad de los agentes de desarrollar horizontes de largo plazo y, por lo tanto, de llevar a cabo transacciones intertemporales eficientes. De acuerdo con estos autores, la inestabilidad sufrida por Argentina fue uno de los motivos por los cuales su política pública ha tendido a ser cortoplacista, desalentando los incentivos a invertir.

Desde el primer presidente constitucional elegido luego de la unificación con Buenos Aires, Argentina tuvo 34 presidentes (tres de ellos reelegidos), de los cuales solo 16 pudieron terminar su mandato (y 3 fueron presidentes provisionales, designados por unos pocos días o meses). Durante ese mismo período de tiempo, los golpes militares llevaron al poder a 13 presidentes de facto.

${ }^{20}$ En Argentina, una reforma constitucional requiere seguir ciertas pautas establecidas en el art. 30 de su CN. No obstante, estos requisitos no siempre fueron respetados. Ejemplos de ello fueron las reformas de 1957 y de 1972. En la primera, se introdujeron modificaciones sin que mediara una ley del Congreso que declarara su necesidad, ya que el gobierno militar de turno había disuelto al poder legislativo. En 1972, otro gobierno militar de facto introdujo las reformas sin ley del Congreso ni funcionamiento de convención nacional constituyente alguna. En 1956, un gobierno militar de facto declaró vigente las Constituciones provinciales anteriores al régimen depuesto, dejando sin efecto las Constituciones sancionadas para las provincias del Chaco, La Pampa y Misiones, restituyendo a catorce provincias sus Constituciones caducas por las reformas constitucionales de 1949 y privando a tres provincias de su Constitución. 
La frecuencia con la que se produjeron interrupciones del orden institucional en Argentina creció sustancialmente a mediados del siglo XX. Tras el golpe de estado que en septiembre de 1930 derrocó al gobierno democrático de Hipólito Yrigoyen, y durante más de 50 años, Argentina fue escenario de continuas fluctuaciones políticas e institucionales. Además, durante algunos de los gobiernos constitucionales se observaron irregularidades tales como fraudes y proscripciones de partidos políticos o personas.

Estas interrupciones generaron una gran inestabilidad política, puesta de manifiesto en una duración extremadamente breve de los mandatos de presidentes, legisladores y gobernadores.

Teniendo presentes estas cuestiones, el criterio adoptado para cuantificar esta variable fue el siguiente: cuando hubo una interrupción del orden institucional se asignaron 0 puntos, mientras que recibieron un puntaje de 10 aquellos años en los que predominaron los gobiernos constitucionales, con elecciones limpias ${ }^{21}$. Cuando hubo irregularidades tales como fraudes y proscripciones a partidos o personas, se asignaron 5 puntos $^{22}$.

\section{Estado de sitio (ES)}

La declaración del ES otorga al presidente ciertas facultades extraordinarias que afectan a derechos y garantías constitucionales. De manera que, una sobreutilización de esta herramienta podría encontrarse vinculada a un incremento en el margen de discrecionalidad del poder ejecutivo nacional, lo cual contribuiría a mantener la calidad institucional de un país en un nivel poco deseable.

Según la CN, la declaración del ES puede emitirse ante dos circunstancias: cuando haya un ataque exterior o en situaciones de conmoción interior que pongan en peligro el ejercicio de la Constitución y de las autoridades creadas por ella (art. $23 \mathrm{CN}$ ). En caso de ataque exterior, el presidente está facultado a declarar el ES con acuerdo del Senado; pero, en caso de conmoción interior, el presidente sólo puede hacerlo si el Congreso se encuentra en receso. Aún así, frente a una declaración presidencial de ES, el Congreso, al reunirse nuevamente, puede aceptar o no esa decisión (art. 61, art. 75 inc. 29 y art. 99 inc. $16 \mathrm{CN})$.

Para construir la variable ES, se evaluaron el marco dentro del cual fueron decididos, así como su alcance, de manera tal que se asignaron 6,66

21 Siguiendo a Molinelli, Palanza y Sin (1999), definimos como gobiernos constitucionales a aquellos durante los cuales la presidencia fue ocupada por personas elegidas conforme a las normas vigentes, por elecciones populares o por reemplazos, conforme a lo dispuesto por aquellas reglas y con funcionamiento pleno del Congreso. Además, si la interrupción se produjo con posterioridad al 30 de junio, se considera que durante ese año hubo democracia.

22 Hubo proscripciones al expresidente Alvear para presentarse como candidato a presidente en 1931; desde 1955, al Partido Peronista y a muchos de sus dirigentes hasta 1960 o 1963/65, según el caso, y hasta 1973 para J. D. Perón; y al Partido Comunista y otros marxistas cada tanto desde 1973. 
puntos a los ES que fueron decididos por el Congreso o por decreto presidencial cuando el Congreso se encontraba en receso y 3,33 puntos a aquellos casos en los que, por la fecha en que fueron declarados, no está claro si el presidente se adelantó a la pronta reunión del Congreso o si esperó a que este finalizara sus sesiones. También hubo episodios en los que el Congreso no estaba en receso y, a pesar de ello, el presidente declaró el ES. A pesar de que el Congreso validó aquella decisión con posterioridad, estos casos recibieron 0 puntos, en vista del aumento del poder del presidente en su atribución de decretarlo. Aquellos años en los que no se recurrió a esta herramienta recibieron una valoración de 10 puntos.

En relación con el alcance de los ES, cuando no hubo se asignaron 10 puntos. Cuando un ES afectó a un 25\% de las provincias, se asignaron 7,5 puntos. Cuando este porcentaje se elevó a un 50\% de las provincias, 5 puntos. Y 2,5 cuando el porcentaje fue de hasta un 75\% de las provincias. En los casos en los que el ES tuvo alcance nacional se asignaron 0 puntos.

\section{Intervenciones federales (IF)}

La CN (art. 6) estipula la posibilidad de una intervención federal en el territorio de las provincias como un instrumento de emergencia destinado a garantizar la forma republicana de gobierno, cuando sea necesario repeler invasiones exteriores $\mathrm{y}$, a petición de las autoridades de la provincia para sostenerlas o restablecerlas si hubiesen sido depuestas por sedición o por invasión de otra provincia.

Al igual que en el caso de los estados de sitio, la $\mathrm{CN}$ establece que el órgano decisor es el Congreso, pudiendo el presidente decretar una IF sólo cuando este se encuentre en receso, con la obligación de convocarlo a sesiones extraordinarias. El Congreso puede aceptar o rechazar la decisión del presidente.

Autores como Vítolo (2007) y Bidegain (1995) sostienen que, a lo largo de la historia argentina, la IF ha sido utilizada con demasiada frecuencia como un arma para resolver pleitos partidistas o para eliminar gobiernos desafectos, y que ha sido uno de los elementos en los que se apoyó el crecimiento de la autoridad presidencial: «...hemos desnaturalizado la institución haciendo una aplicación abusiva y anticonstitucional de ella, convirtiéndola en un instrumento de avasallamiento de las autonomías provinciales en procura de gobiernos locales adictos al sector político que ejerce el Gobierno Nacional» ${ }^{23}$.

Molinelli, Palanza y Sin (1999) señalan, además, que, al ser el presidente quien nombra al interventor y le da instrucciones, en cualquier caso implica un aumento temporario e importante del poder presidencial. Este exceso de capacidad de intervención supone una mayor discrecionalidad que podría

${ }^{23}$ Vítolo (2007, p. 13). 
poner en duda el cumplimiento de compromisos por parte del poder político, tiñendo de incertidumbre el respeto de los derechos de propiedad.

Para construir la variable IF se asignaron 5 puntos a las decididas por el Congreso o por decreto presidencial, cuando el Congreso estaba en receso, y 0 puntos a las situaciones en las que fueron decididas por el presidente aun cuando el Congreso se encontraba en sesiones. Los años en los que no se utilizó esta herramienta recibieron 10 puntos.

En cuanto a la cantidad de provincias intervenidas se siguió el mismo criterio que el empleado al construir la variable ES.

\section{Justicia}

En Argentina, el poder judicial es una de las tres ramas de gobierno y se encuentra encabezada por la Corte Suprema de Justicia de la Nación (CSJN).

Puesto que la $\mathrm{CN}$ promueve un sistema político fragmentado, sería razonable presumir un poder judicial independiente, capaz de operar con autonomía. Sin embargo, la justicia en Argentina no siempre fue considerada de esta forma, situación que probablemente haya impactado negativamente en la calidad de sus instituciones - de nada sirve un marco legal apropiado cuando no existe un órgano de contralor confiable que supervise su cumplimiento.

La evolución histórica de la CSJN ha estado marcada por frecuentes cambios en su composición. Luego de la primera presidencia de Juan Domingo Perón, los regímenes de facto y democráticos que lo sucedieron pudieron reemplazar a los miembros de la Corte con relativa facilidad. Los jueces fueron removidos, el número de miembros de la Corte fue aumentado y disminuido y, en general, los presidentes tuvieron la posibilidad de gobernar con Cortes Supremas relativamente amigables. Gallo y Alston (2008, p. 180) sostienen que fue el gobierno de Perón el que introdujo reformas que suprimieron la independencia judicial en Argentina y dieron lugar a un ciclo de cambios continuos en el sistema judicial. Y si analizamos la evolución en la composición de la CSJN, la evidencia parece respaldar esta afirmación, por cuanto a partir de 1945, en la mayoría de los casos, los cambios los ocasionó la destitución de los miembros de la Corte que sobrevino a gran parte de los golpes de Estado ${ }^{24}$.

La CN establece que los jueces de la CSJN sean designados por el presidente de la nación con acuerdo del Senado y que permanezcan en su cargo mientras tengan buena conducta (art. $110 \mathrm{CN}$ ). Si bien la Constitución de

24 Hasta 1945, la mayoría de los jueces nombrados (el $84 \%$ ) se jubilaron o fallecieron en la Corte. De un total de 38 ceses, 32 correspondieron a fallecimientos o jubilaciones. A partir de 1945/ 46 comienza a derrumbarse este proceso: durante el período 1946-2006, de un total de 65 ceses, únicamente cuatro tuvieron como causal el fallecimiento de jueces y solo uno se debió a jubilación. El período histórico con menor estabilidad fue 1947-1983: durante ese lapso se sucedieron 46 jueces, algunos de los cuales no llegaron a durar un año en funciones. 
1994 dispone la exigencia de un nuevo nombramiento una vez cumplidos los 75 años - por el plazo de cinco años, pudiendo ser renovado indefinidamente (art. 99, inc. 4, párrafo $3^{\circ}$ )—, esta disposición no se aplica y sus magistrados solo pueden ser removidos por juicio político llevado a cabo en el Senado y, exclusivamente, bajo el cargo de mal desempeño de sus funciones ${ }^{25}$.

Por otro lado, el número de miembros de la Corte se establece por ley y, desde 1863 hasta la fecha, osciló entre cinco y nueve miembros ${ }^{26}$.

La variable «justicia» fue construida teniendo en cuenta lo dispuesto por la $\mathrm{CN}$ respecto a los mecanismos de designación y remoción de jueces, de manera tal que se asignaron 10 puntos a aquellos años en los que o bien no hubo cambios en la composición de la Corte o los hubo debido al fallecimiento o la jubilación de algunos de sus miembros. Se asignaron 7,5 puntos cuando se enjuició o renunció menos del $50 \%$ de los jueces que integran la Corte; 5 puntos cuando renunció o se enjuició al 50\% o más; 2,5 puntos en caso de ampliación o reducción del número de miembros de la corte y 0 puntos en caso de remoción. Por otro lado y a efectos de distinguir aquellos años en los que el presidente contó con una Corte adicta, se asignaron 0 puntos a esos casos y 10 a aquellos en los que la Corte fue independiente ${ }^{27}$. Finalmente, se realizó un promedio entre ambos valores.

\section{Libertad de prensa}

La libertad de expresión se encuentra protegida por la CN, que ya en 1853 declaraba que todos los habitantes de la nación gozan del derecho de publicar sus ideas por la prensa sin censura previa (art. $14 \mathrm{CN}$ ), y que el Congreso no dictará leyes que restrinjan la libertad de imprenta o establezcan sobre ella la jurisdicción federal (art. $32 \mathrm{CN}$ ). Estos artículos no fueron modificados por la Reforma Constitucional de 1994, la cual, además, adhirió a un tratado internacional, la Convención Americana sobre Derechos Humanos, que contiene disposiciones relacionadas con la libertad de prensa.

Sin embargo, la evolución de la libertad de prensa en Argentina estuvo sujeta a una serie de vaivenes íntimamente relacionados con los producidos en su vida política, especialmente durante el siglo XX. De acuerdo con Pizarroso Quintero et al. (1994, p. 495), hasta 1940 la prensa argentina había alcanzado su más alto nivel de desarrollo; sin embargo, señalan los autores, a partir del primer gobierno de Perón se vio afectada por la manipulación y el control

${ }^{25}$ La CSJN declaró inválida su incorporación en la reforma constitucional de 1994 al fallar sobre la cuestión en el caso «Fayt» (1999).

26 La normativa actual dispone la composición de la Corte por cinco miembros, volviendo a la composición con la que históricamente contó desde el 15 de enero de 1863. Un decreto ley posterior (1285/58) había elevado este número a siete miembros. En 1966 retornó a cinco y en 1990 volvió a elevarse, esta vez a nueve integrantes.

27 Definimos como "corte adicta» a aquella cuya conformación fue alterada de modo que el 50 $\%$ o más de sus miembros responden al ejecutivo de turno. 
político ejercido tanto por este como por los gobiernos que le sucedieron, y sobre todo por la dictadura militar. Durante los mandatos de Perón y los siguientes se produjeron situaciones difíciles para los medios de comunicación, que sufrieron manipulaciones gubernamentales, clausura de periódicos y una censura como nunca había conocido el país, especialmente en la década de 1970. Luego del pronunciamiento militar del 24 de marzo de 1976, la libertad de prensa perdió completa vigencia ${ }^{28}$.

Una vez restaurada la democracia en el año 1983, la censura a la prensa fue cediendo paulatinamente, alcanzando su pico más alto de libertad durante la década de 1990.

La construcción de esta variable se realizó siguiendo lineamientos propuestos por Freedom House en la construcción de su Índice de Libertad de Prensa ${ }^{29}$. Los puntajes asignados fueron los siguientes: 10 cuando hubo prensa libre, 5 cuando fue parcialmente libre y 0 cuando no hubo libertad de prensa.

\section{Coparticipación de impuestos}

La Constitución de 1853 establecía un claro esquema de separación de fuentes tributarias nación-provincias. No obstante, existía un régimen de transferencias que, a comienzos del siglo XX, implicaba que la nación financiara alrededor de un cinco por cien del gasto público provincial. Por ese entonces, las provincias gozaban de una marcada autonomía tributaria y de independencia financiera.

La crisis de 1930 hizo replantearse el sistema de separación de fuentes, fundamentalmente por la caída de los ingresos fiscales aduaneros, fuente principal de financiamiento del gobierno nacional. Así, en 1935 se instauró un régimen de coparticipación de impuestos por el que las provincias comenzaron a ceder potestades tributarias a la nación que, entre otras cosas, pasó a recaudar y transferir recursos a estas ${ }^{30}$. En la actualidad, las transferencias por coparticipación representan más del 50\% de los ingresos de muchas provincias, e incluso superan el $90 \%$ en provincias como La Rioja o

28 En esta fecha, la Junta de Comandantes Generales hizo saber que sería «reprimido con la pena de reclusión por tiempo indeterminado al que por cualquier medio difundiere, divulgara o propagara comunicados o imágenes provenientes o atribuidos a asociaciones ilícitas o a personas o grupos notoriamente dedicados a actividades subversivas o de terrorismo [...] reprimido con reclusión de hasta 10 años al que por cualquier medio difundiere, divulgara o propagara noticias, comunicados o imágenes con el propósito de perturbar, perjudicar o desprestigiar la actividad de las fuerzas armadas, de seguridad o policiales».

${ }^{29}$ Freedom House es una organización no gubernamental que desde 1980 publica anualmente el informe Freedom of the Press sobre libertad de prensa en todos los países y territorios en disputa en el mundo, que en el año 2009 llegó a 195. Se estima un índice de libertad de prensa en cuya construcción son tenidos en cuenta el ambiente legal, el político y el económico en que se ejerce la libertad de prensa. El puntaje final asignado ubica a cada país en la categoría de "libre", "parcialmente libre" o "no libre".

30 En la actualidad, se rige por la Ley Nacional n ${ }^{\circ} 23.548$ de 1988 , con sus posteriores regímenes modificatorios. 
Formosa, situación que genera una dependencia excesiva de los recursos que le son transferidos desde el gobierno central ${ }^{31}$.

Sanguinetti (2002) señala que uno de los principales determinantes del pobre desempeño fiscal en las provincias argentinas es, precisamente, la inestabilidad de este régimen de distribución de recursos. El autor sostiene, además, que la presencia de rescates por parte del gobierno nacional debilita la restricción presupuestaria de los gobiernos provinciales, lo que genera incentivos para que adopten políticas fiscales inadecuadas. Asimismo, esta falta de correspondencia fiscal contribuye a crear un problema de propiedad común de los recursos, lo que estimula más el gasto que la recaudación, al tiempo que se desalienta un mayor esfuerzo tributario.

Existen opiniones dispares con respecto a la cuestión de la descentralización fiscal, pues se sostiene que podría conducir a situaciones de autonomía de las provincias con mayor capacidad recaudatoria y de dependencia de las provincias con menor capacidad ${ }^{32}$. Sin embargo, y como ya se ha señalado, un sistema excesivamente centralizado genera falta de correspondencia entre la decisión del gasto y el esfuerzo de financiarlo, induciendo una estructura de incentivos perversa y estimulando conductas fiscales imprudentes. En consecuencia, la variable «coparticipación» fue construida considerando la correspondencia fiscal como la situación ideal, y se asignaron los puntajes de acuerdo con el esquema propuesto en el Cuadro 2.

\section{Presupuesto}

El presupuesto nacional surge como resultado de un proceso de decisión colectivo en el que intervienen los diferentes ministerios del poder ejecutivo y los integrantes del Congreso de la nación ${ }^{33}$. Unos tienen incentivos para expandirlo, mientras que otros, para internalizar los costos de llevar a cabo políticas deficitarias.

De acuerdo con Alesina et al. (1999), la evidencia empírica sugiere que un proceso presupuestario centralizado mayormente en el poder ejecutivo, a través de un Ministerio de Economía fuerte, en el que predominen reglas más jerárquicas y transparentes, favorece el sostenimiento del equilibrio fiscal.

31 Cálculo propio de acuerdo a información publicada por la Dirección Nacional de Coordinación Fiscal con las Provincias. Primer semestre, año 2008.

32 Véase, por ejemplo, Raimundi y Tilli (1996).

33 La Oficina Nacional de Presupuesto recibe los anteproyectos de presupuesto de las distintas instituciones de la Administración Pública nacional. Basándose en ellos, en los resultados de años anteriores y en las políticas y objetivos contemplados en los programas del gobierno, esta oficina lleva a cabo un proceso que culmina con la formulación del Proyecto de Ley del Presupuesto, que luego es remitido al Congreso de la nación para su aprobación. En la etapa de formulación del Presupuesto, y antes de su remisión al Congreso, intervienen la Jefatura de Gabinete y el presidente de la nación, pero solo el Congreso tiene la facultad de aprobarlo, siendo su responsabilidad juzgar la validez del programa de gobierno contenido en el mismo. 
CUADRO 2

CRITERIOS ADOPTADOS PARA CONSTRUIR LA VARIABLE COPARTICIPACION

\begin{tabular}{|c|c|c|}
\hline \multirow{4}{*}{$\begin{array}{l}\text { Según fuente y distribución } \\
\text { de los recursos: }\end{array}$} & Respuesta posible & Puntaje \\
\hline & $\begin{array}{l}\text { La nación solo recauda impuestos sobre el } \\
\text { comercio exterior y algunos impuestos internos, } \\
\text { de acuerdo a lo establecido en la Constitución }\end{array}$ & 10 \\
\hline & $\begin{array}{l}\text { La nación recauda algunos impuestos y } \\
\text { luego los redistribuye, mientras que las } \\
\text { provincias conservan la recaudación de } \\
\text { otros en exclusividad }\end{array}$ & 5 \\
\hline & $\begin{array}{l}\text { La nación recauda todos los impuestos y } \\
\text { luego redistribuye }\end{array}$ & 0 \\
\hline \multirow[t]{4}{*}{ Según criterio de reparto } & Cada quién gasta en función de lo que recauda & 10 \\
\hline & $\begin{array}{l}\text { Ponderadores calculados teniendo en cuenta } \\
\text { criterios de eficiencia y equidad } \rightarrow \text { Sistemas } \\
\text { devolutivos }\end{array}$ & 6,66 \\
\hline & $\begin{array}{l}\text { Ponderadores calculados a partir de } \\
\text { aspectos coyunturales de cada provincia } \rightarrow \\
\text { Sistemas redistributivos }\end{array}$ & 3,33 \\
\hline & $\begin{array}{l}\text { Promedio de los aportes del Tesoro Nacional } \\
\text { recibidos por cada provincia } \rightarrow \text { Sistemas } \\
\text { discrecionales }\end{array}$ & 0 \\
\hline
\end{tabular}

Fuente: Ver texto

Nota: Si bien el régimen de coparticipación quedó instaurado por ley en el año 1935, durante el período 1860-1934 existió de hecho un régimen de recaudación y transferencias nación-provincias que se tomó en cuenta para la construcción de esta variable.

Para medir el impacto de las instituciones presupuestarias en la evolución de la calidad institucional de Argentina, se construyó un subíndice siguiendo la metodología propuesta por Alesina et al. (1999) reseñada en el subapartado 3.1, que combina elementos referidos a las restricciones, la jerarquía y la transparencia en el presupuesto. La idea que subyace a este indicador es que las instituciones presupuestarias más restrictivas, tanto en términos de límites numéricos a los resultados fiscales como de mayor jerarquía a favor de aquellos que tienen más incentivos para mantener las finanzas controladas, generan menores déficits.

El Cuadro 3 presenta el cuestionario modelo a partir del cual se construyó la variable "presupuesto", adaptado de Alesina et al. (1999). 


\section{CUADRO 3}

CRITERIOS ADOPTADOS PARA CONSTRUIR LA VARIABLE PRESUPUESTO

\begin{tabular}{|c|c|c|}
\hline Pregunta 1 & $\begin{array}{l}\text { ¿Existen restricciones constitucionales sobre el } \\
\text { financiamiento del gasto? }\end{array}$ & Puntaje \\
\hline & Ninguna & 0,00 \\
\hline & La Constitución estipula el financiamiento adecuado & 5,00 \\
\hline & El déficit debe ser cero & 10,00 \\
\hline \multirow[t]{4}{*}{ Pregunta 2} & $\begin{array}{l}\text { ¿Existe algún requerimiento legal sobre la aprobación } \\
\text { de un programa macro que sea previo a la presentación } \\
\text { del presupuesto al Congreso? ¿Cuán importante es? }\end{array}$ & \\
\hline & No es importante/ No es requerido & 0,00 \\
\hline & $\mathrm{Si}$, es relativamente importante & 5,00 \\
\hline & Si, es muy importante & 10,00 \\
\hline \multirow[t]{5}{*}{ Pregunta 3} & $\begin{array}{l}\text { ¿Qué clase de restricciones al endeudamiento tiene el } \\
\text { gobierno? }\end{array}$ & \\
\hline & Sin restricciones, el gobierno se endeuda si lo necesita & 0,00 \\
\hline & El Congreso aprueba cada operación & 3,33 \\
\hline & Techo puesto por el gobierno & 6,66 \\
\hline & Techo puesto por el Congreso & 10,00 \\
\hline \multirow[t]{4}{*}{ Pregunta 4} & $\begin{array}{l}\text { ¿Tiene el ministro de Economía más autoridad que los } \\
\text { otros ministros en lo que respecta al presupuesto? }\end{array}$ & \\
\hline & Igual o casi igual que los demás & 0,00 \\
\hline & Algo mayor que la de otros ministros & 5,00 \\
\hline & Considerablemente mayor que la de otros ministros & 10,00 \\
\hline \multirow[t]{5}{*}{ Pregunta 5} & $\begin{array}{l}\text { Restricciones sobre los cambios que el Congreso puede } \\
\text { hacer al presupuesto presentado: el Congreso solo } \\
\text { puede proponer enmiendas }\end{array}$ & \\
\hline & Sin ninguna restricción & 0,00 \\
\hline & Que no incrementen el déficit o el gasto & 3,33 \\
\hline & Para aumentar el gasto, con la aprobación del gobierno & 6,66 \\
\hline & Que no incrementen el déficit ni el gasto & 10,00 \\
\hline \multirow[t]{3}{*}{ Pregunta 6} & ¿Qué sucede si el Congreso rechaza el presupuesto? & \\
\hline & No se habilitan fondos & 0,00 \\
\hline & Se usa el presupuesto del año anterior & 5,00 \\
\hline
\end{tabular}


CUADRO 3 (Cont.)

\begin{tabular}{|l|l|c|}
\hline & Se usa el presupuesto propuesto por el gobierno & 10,00 \\
\hline Pregunta 7 7 & $\begin{array}{l}\text { ¿Puede modificarse el presupuesto después de la } \\
\text { aprobación del Congreso? }\end{array}$ & \\
\hline & Por iniciativa del gobierno, sin aprobación del Congreso & 0,00 \\
\hline & Por iniciativa del gobierno, con aprobación del Congreso & 5,00 \\
\hline & No & 10,00 \\
\hline & $\begin{array}{l}\text { ¿El gobierno está facultado, legalmente, para cortar el } \\
\text { gasto después de que el presupuesto ha sido } \\
\text { aprobado? }\end{array}$ & \\
\hline & No & 0,00 \\
\hline & A discreción del gobierno, sobre cualquier ítem & 3,33 \\
\hline & Para gastos no encuadrados & 6,66 \\
\hline Pregunta 9uando los ingresos son mas bajos que los proyectados & 10,00 \\
\hline & $\begin{array}{l}\text { ¿Asume el gobierno central deudas contraídas } \\
\text { originalmente por otras dependencias públicas? }\end{array}$ & \\
\hline & Frecuentemente, incluyendo deuda no garantizada & 0,00 \\
\hline & Excepcionalmente & 5,00 \\
\hline & Ocasionalmente, solo deuda garantizada & 10,00 \\
\hline
\end{tabular}

Fuente: Ver texto

\section{Independencia del banco central}

En ocasiones, los gobiernos afrontan incentivos que podrían conducirlos a aumentar la oferta de dinero por encima de las necesidades que surgirían de un crecimiento no inflacionario de la economía. Por ejemplo, podrían desear abaratar artificialmente la moneda nacional y aumentar el nivel de exportaciones y de empleo, o quizás para financiar el déficit fiscal. Cukierman (1992) sostiene que un banco central independiente equilibra al poder ejecutivo y constituye un ingrediente básico de un gobierno con límites claros, lo que contribuye a que exista más democracia y al fortalecimiento de la estructura institucional.

La relación que existe entre la independencia del banco central y la inflación ha sido objeto de extensas investigaciones. Al respecto, podemos leer Alesina y Summers (1993), Cukierman (1992) y Cukierman, Webb y Neyapti (1992), entre otros. La evidencia de esas diferentes investigaciones empíricas es coherente con la conclusión de que inflación e independencia efectiva del banco central se relacionan en forma negativa, tanto en países desarrollados como en desarrollo. 
Actualmente el Banco Central de la República Argentina (BCRA) mantiene relaciones con el poder ejecutivo a través del Ministerio de Economía y no debería estar sujeto a sus órdenes, indicaciones o instrucciones ${ }^{34}$.

Para intentar capturar su independencia y de acuerdo a los antecedentes revisados, se utilizó la tasa de inflación como variable proxy, lo cual nos permite, además, sortear el problema de la no existencia de este organismo hasta mayo de $1935^{35}$.

El criterio adoptado fue el siguiente: los años que sufrieron una inflación anual menor al 5\% recibieron 10 puntos; 6,66 en los casos en los que la inflación osciló entre un 5\% y un 10\% anual; 3,33 puntos cuando se ubicó entre un $10 \%$ y un $20 \%$ anual y 0 cuando se superó esta última cifra.

\subsection{Construyendo un «indicador institucional»}

Una vez concluida la etapa de identificación y construcción de las variables se optó por el análisis de componentes principales (ACP) como metodología de agregación $^{36}$. Esta técnica multivariada es una de las más utilizadas para la construcción de índices, especialmente en los casos en los que no existe consenso sobre la importancia relativa de las variables que lo conforman.

El ACP busca un factor latente a partir de dimensiones observables; si las variables seleccionadas reflejan, verdaderamente, la calidad de las instituciones se podrá construir un índice mediante una combinación lineal de las mismas. La utilización del ACP solo tiene sentido si existen altas correlaciones entre las variables, señal de que existe información redundante y, por tanto, pocos factores podrían explicar gran parte de la variabilidad total.

El Gráfico 1 muestra el índice de calidad institucional logrado, junto con su componente tendencial obtenido mediante el filtro de Hodrick-Prescott

34 El BCRA fue creado el 31 de mayo de 1935 por la Ley 12.155, confiriéndole una serie de funciones que hasta entonces se encontraban dispersas y a cargo de distintas instituciones y organismos públicos. Nació como una entidad independiente; pero en septiembre de 1949 pasó a ser una entidad autárquica, dependiente del poder ejecutivo a través del Ministerio de Finanzas (Ley 13.571). En 1991 se realizaron importantes reformas financieras, tendientes a una mayor apertura económica y en septiembre de 1992 se sancionó la Ley 24.144 que consagraba de nuevo la independencia del banco central y establecía su autarquía (art. 1). A sus autoridades las nombra el presidente de la nación con acuerdo del Senado (art. 7, D. 1373/99).

${ }^{35}$ Un dato que no es trivial es que, cuando se analiza la evolución de la tasa de inflación en Argentina, se observan sus mayores valores y una mayor variabilidad durante el período de dependencia del BCRA (1949-1991).

${ }^{36}$ De acuerdo a lo indicado en el subapartado 3.1, inicialmente se plantearon dos metodologías alternativas para construir el Índice: la suma simple de todas las variables —metodología propuesta por Alesina et al. (1999) — y el Análisis de Componentes Principales (ACP). Por cuestiones de espacio, en este artículo se incorpora únicamente la estimación a través del ACP, aunque ello no sería un problema, de acuerdo a lo señalado por Voigt (2007, p. 20) sobre la conveniencia de utilizar esta técnica. Además se realizaron ejercicios de robustez tendientes a validar el indicador construido, cuyos resultados corroboran esta afirmación y se encuentran disponibles a requerimiento de los interesados. 


\section{GRÁFICO 1}

ÍNDICE DE CALIDAD INSTITUCIONAL PARA ARGENTINA, PERÍODO 1862-2008 (valores normalizados)

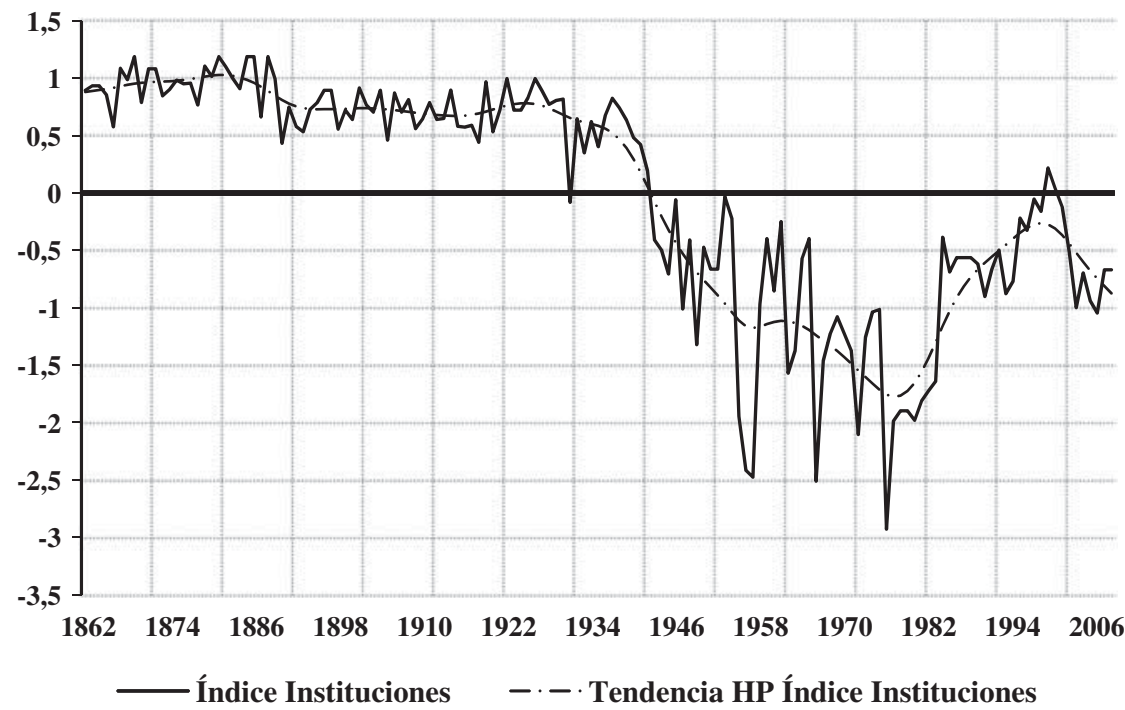

Fuente: Ver texto

(tendencia HP) ${ }^{37}$. Los valores del índice se normalizaron para simplificar su lectura, obteniendo una serie con media 0 y desviación estándar 1 . Así, cuando el indicador toma el valor 0 nos encontramos en el promedio de calidad institucional, valores positivos indican mayor calidad, mientras que los negativos indican que la calidad de las instituciones se encuentra por debajo de los estándares.

De acuerdo con el Gráfico 1, el período 1862-1930, de relativa estabilidad, registra el momento de mejor desempeño del indicador con valores que son positivos durante toda la etapa. Esta fase se interrumpe con la primera caída significativa del índice en el año 1931, luego del golpe militar que derrocó al

37 Previamente, se verificó la posibilidad de utilizar la técnica del ACP mediante el análisis del determinante de la matriz de correlaciones, que arrojó un valor de 0,00. Esta circunstancia indica que las variables utilizadas se encuentran linealmente relacionadas, lo que implicaría que el análisis factorial es una técnica válida para analizar esas variables. Además, la medida de adecuación muestral KMO, cuyo valor es superior a 0,50, confirma la viabilidad de aplicar este método. Finalmente, la prueba de esfericidad de Barlett rechaza la hipótesis nula de que la matriz de correlaciones es una matriz identidad —en cuyo caso, no existirían correlaciones significativas entre las variables y el modelo factorial no sería pertinente-, por lo que, también de acuerdo a este criterio, estaríamos en condiciones de utilizar el ACP. 
gobierno constitucional de Hipólito Yrigoyen. A partir de ese momento, y pese a que sus valores permanecen positivos durante una década más, el indicador cambia su tendencia e inicia una fase de declinación. También en esta etapa, comienza a experimentar una mayor y creciente inestabilidad: «...fue la crisis de 1930 la que concluyó definitivamente la belle époque y creó las instituciones de un mundo distinto» señala Cortés Conde (2005, p. 53).

A partir de 1943, con los militares nuevamente en el poder, el índice continúa su tendencia decreciente y sus valores se tornan negativos, situación que se ve acentuada durante los dos gobiernos consecutivos del general Juan Domingo Perón -1946-1951 y 1951-1955-. «La destitución de la Corte Suprema [1947], que representaba un obstáculo a las políticas populistas, y la introducción de la Constitución de 1949, destruyeron la separación de poderes e implicaron que los derechos de propiedad ya no estarían protegidos por el imperio de la ley», señalan Prados y Sanz $(2009 \text {, p. } 8)^{38}$ En tanto que Cortés Conde (2005, p. 47) sostiene: «Aunque mucho había cambiado desde la crisis de 1930, nada influyó tanto como el peronismo en la vida argentina de la segunda mitad del siglo [...] la creación de un marco institucional nuevo fue, sin duda, resultado del peronismo».

El período 1955-1976 se caracteriza por la elevada volatilidad del indicador y porque durante esa etapa alcanza sus valores más bajos. Posteriormente, se observa una paulatina mejora, aunque sus valores continúan siendo negativos y se encuentran alejados de la media. A finales de la década de 1990, el índice vuelve a lograr niveles positivos; aunque la recuperación es breve y el nuevo siglo sobreviene con un deterioro de la calidad institucional.

A la luz de esta evidencia, parece de interés analizar el comportamiento del indicador por subperíodos: 1862-1930 de la organización nacional, 1931-1983 de las interrupciones militares, y 1984-2008 del retorno a la democracia. Si bien esta división fue establecida en base a la inspección gráfica del indicador, también existe, como puede apreciarse, una correspondencia con eventos históricos que sustentarían esta elección. Véanse los datos del Cuadro 4.

Durante la etapa que va desde 1862 hasta 1930, el índice alcanza su máximo histórico $(1,19)$ así como un valor promedio más elevado $(0,83)$ que el que se observa en los períodos subsiguientes $(-0,83$ y $-0,53)$. Al tratarse de una variable normalizada, podemos concluir que en este período la calidad institucional se hallaba por encima del estándar. Simultáneamente, esta etapa coincide con la de menor volatilidad del indicador.

En el segundo subperíodo, 1931-1983, el valor medio del índice se torna negativo $(-0,83)$, lo que indica que la calidad de las instituciones se encontraba por debajo del nivel promedio. Al mismo tiempo, su volatilidad se multiplica pasando de 0,18 a 0,99 .

${ }^{38}$ Traducción del autor. 
CUADRO 4

ÍNDICE DE INSTITUCIONES, POR SUBPERÍODOS

\begin{tabular}{|l|c|c|c|}
\hline & \multicolumn{3}{|c|}{ Índice de Calidad Institucional } \\
\hline Media & $\mathbf{1 8 6 2 - 1 9 3 0}$ & $\mathbf{1 9 3 1 - 1 9 8 3}$ & $\mathbf{1 9 8 4 - 2 0 0 8}$ \\
\hline Desviación estándar & 0,83 & $-0,83$ & $-0,53$ \\
\hline Mínimo & 0,18 & 0,99 & 0,33 \\
\hline Máximo & 0,43 & $-2,93$ & $-1,05$ \\
\hline Kruskal-Wallis & 1,19 & 0,83 & 0,22 \\
\hline
\end{tabular}

Fuente: cálculos propios

* Valores correspondientes a chi cuadrado; p-value 1\% rechaza la hipótesis nula de igualdad de la población.

La etapa final, 1984-2008, evidencia una ligera mejora en el valor medio del indicador $(-0,53)$ y una reducción de su volatilidad, aunque sus niveles permanecen por debajo de los estándares ${ }^{39}$.

En términos generales, este patrón parece ajustarse al comportamiento de los indicadores institucionales CIM de Prados y Sanz (2009) e IRLE de Sanz (2009). En ambos casos - y de manera coincidente con lo evidenciado por nuestro indicador - la etapa de mejor desempeño institucional coincide con el período previo a 1930, durante el cual, según estos autores, Argentina disfrutó de una transición a una democracia abierta, justicia independiente y clara separación de poderes. Los años que siguieron a 1931-1933 muestran una tendencia decreciente, que se acentúa a partir 1943. El CIM comienza a recuperarse en 1961 y alcanza su pico en el año 2001. En tanto que el IRLE alcanza sus valores más bajos después de 1974 y no muestra signos de recuperación hasta la década de1990.

\subsection{Instituciones y crecimiento}

Cuando comparamos las tendencias de crecimiento del PBI per cápita de Argentina con las del indicador construido en este trabajo, se observa que el período de mayor calidad institucional coincide con el de mayor crecimiento de su producto por habitante (1862-1930). El Cuadro 5 muestra las tasas de crecimiento promedio del PBI per cápita argentino por subperíodo, así como las diferencias respecto a las tasas de crecimiento de un grupo de países avanzados —Estados Unidos y otros países desarrollados—. De aquí surge que,

39 Adicionalmente, se utiliza la prueba de Kruskal Wallis para determinar si los tres períodos analizados varían entre sí. Los resultados confirman que el Índice proviene de distribuciones diferentes; es decir, que difiere significativamente entre los períodos 1862-1930, 1931-1983 y 1984-2008. 


\section{CUADRO 5}

CRECIMIENTO ANUAL PER CÁPITA Y RELATIVO DE ARGENTINA AÑOS 1870-2008, POR SUBPERÍODOS

\begin{tabular}{|c|c|c|c|c|c|c|c|c|c|}
\hline & \multicolumn{3}{|c|}{$\begin{array}{c}\text { Tasa de crecimiento } \\
\text { anual PBI } p c \\
\text { Argentina }\end{array}$} & \multicolumn{3}{|c|}{$\begin{array}{c}\text { Diferencia Tasa de } \\
\text { crecimiento anual PBI } \\
\text { pc EE.UU. - PBI } p c \\
\text { Argentina }\end{array}$} & \multicolumn{3}{|c|}{$\begin{array}{c}\text { Diferencia Tasa de } \\
\text { crecimiento anual PBI } \\
\text { pc desarrollados - PBI } \\
\text { pc Argentina }\end{array}$} \\
\hline & $\begin{array}{l}1870- \\
1930\end{array}$ & $\begin{array}{l}1931- \\
1983\end{array}$ & $\begin{array}{l}1984- \\
2008\end{array}$ & $\begin{array}{l}1870- \\
1930\end{array}$ & $\begin{array}{l}1931- \\
1983\end{array}$ & $\begin{array}{l}1984- \\
2008\end{array}$ & $\begin{array}{l}1870- \\
1930\end{array}$ & $\begin{array}{l}1931- \\
1983\end{array}$ & $\begin{array}{l}1984- \\
2008\end{array}$ \\
\hline Media & 0,02 & 0,011 & 0,014 & $-0,001$ & 0,01 & 0,006 & $-0,005$ & 0,012 & 0,004 \\
\hline $\begin{array}{l}\text { Desviación } \\
\text { Estándar }\end{array}$ & 0,08 & 0,04 & 0,06 & 0,088 & 0,078 & 0,065 & 0,079 & 0,049 & 0,064 \\
\hline
\end{tabular}

Fuente: cálculos propios a partir de datos de Cortés Conde (1994) y Angus Maddison, University of Groningen, Statistics on World Population, GDP and per capita GDP, 1-2008 AD available on Internet at: http://www.ggdc.net/maddison/oriindex.htm

Nota: Los países desarrollados son Austria, Bélgica, Dinamarca, Finlandia, Francia, Alemania, Italia, Noruega, Países Bajos, Reino Unido, Suecia y Suiza.

durante el período 1870-1930, Argentina creciera a una tasa mayor que los países más ricos - dado el diferencial negativo de tasas- y experimentara la etapa de mayor expansión, creciendo a una tasa promedio anual del $2 \%$.

Entre 1931 y 1983, la tasa de crecimiento promedio de Argentina cae a $1,1 \%$, y es menor que las de Estados Unidos y los restantes países desarrollados, situación que se evidencia mediante el incremento en el diferencial de tasas. Finalmente, durante el período 1984-2008, la tasa de crecimiento promedio de Argentina aumenta al 1,4\%, aunque continúa siendo menor que la experimentada por los países más ricos.

Veamos ahora el Gráfico 2, que muestra la relación entre el índice de calidad institucional y el comportamiento relativo de Argentina medido por las ratios entre su PBI per cápita y el de Estados Unidos, y entre su PBI per cápita en relación con el de otros países desarrollados.

Inicialmente, se percibe una asociación positiva entre instituciones y comportamiento relativo, así como la existencia de dos grupos de nubes de puntos diferenciados. Parece que existe un antes y un después del año 1942; hasta ese momento, tanto el indicador de calidad institucional como las ratios de los PBI per cápita son elevados. Sin embargo, a partir de ese año se aprecia una gran dispersión en los valores que toma el índice, así como una caída gradual en el nivel de las ratios de PBI.

Esta situación abre un gran interrogante que aún no ha sido respondido de manera contundente por la literatura: ¿cuánto tiempo es necesario que transcurra para que una mejora $-\mathrm{o}$ un deterioro- en la calidad institucional impacte sobre el crecimiento de un país? Quizás lo que el Gráfico 2 está mostrando es precisamente esto, es decir, que el impacto de un cambio institucional no es instantáneo y, de la misma forma que el deterioro institucional iniciado en 


\section{GRÁFICO 2 \\ COMPORTAMIENTO RELATIVO DE ARGENTINA PERÍODO 1870-2008}

(a)

Argentina vs. EE.UU
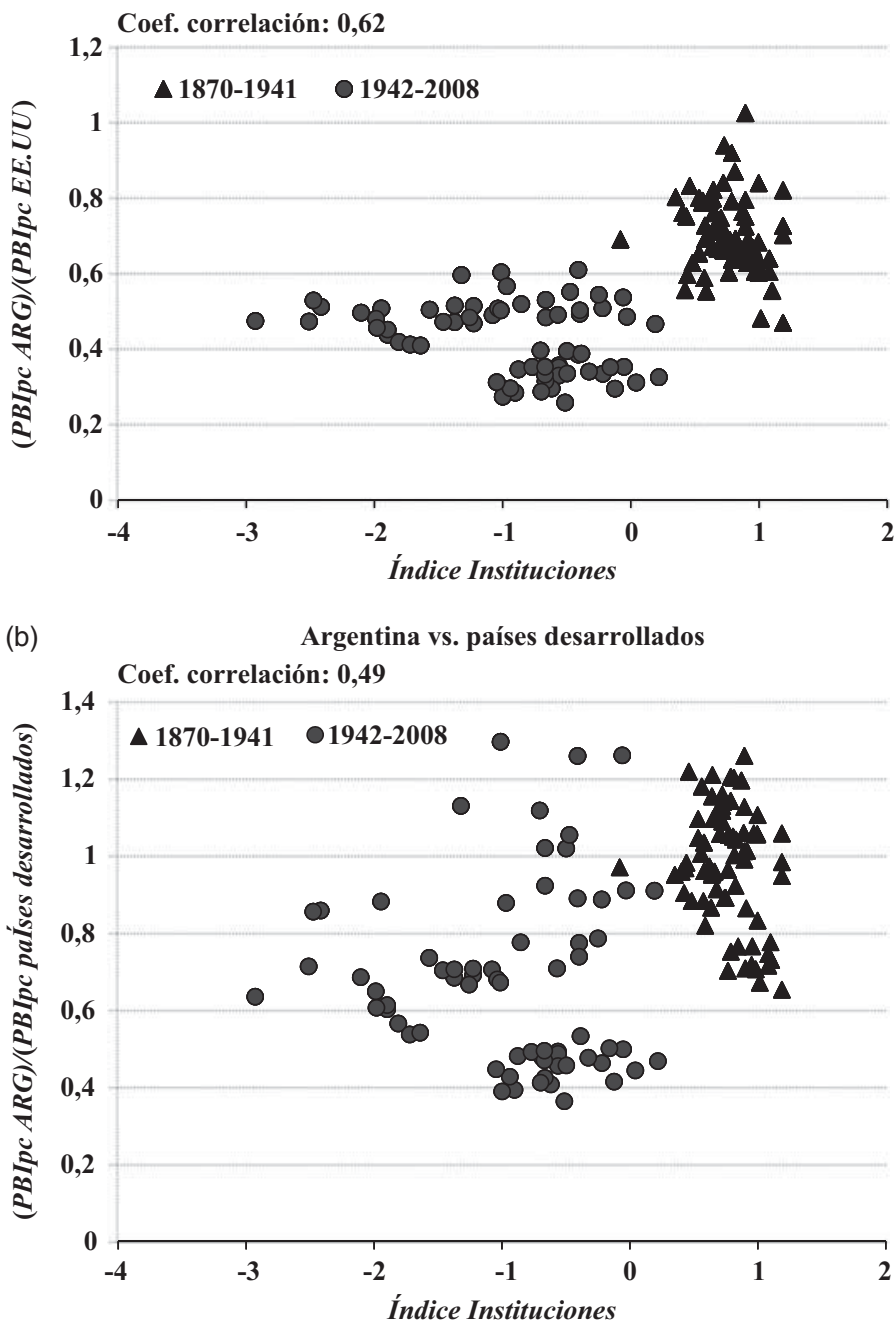

Fuente: Elaboración propia. PBI per cápita de Cortés Conde (1994) y Angus Maddison, University of Groningen, Statistics on World Population, GDP and per capita GDP, 1-2008 AD available on Internet at: http://www.ggdc.net/maddison/oriindex.htm

Nota: Puesto que al graficar las nubes de puntos parecían distinguirse dos grupos, se decidió hacer explícita esa diferencia utilizando símbolos diferenciados que ayudaran a visualizar esta circunstancia. 
1930 se agudizó luego de transcurrir más de una década, quizás la mejora evidenciada en el indicador al finalizar el siglo XX requiera de más tiempo para que pueda tener un impacto positivo en la posición relativa de Argentina.

Ciertamente, en un artículo reciente, Bluhm y Szirmai (2012) realizan una minuciosa revisión de la literatura sobre instituciones y crecimiento económico, poniendo especial atención en la identificación de las relaciones causales subyacentes, los métodos empíricos y el tipo de datos utilizados. Estos autores encuentran un fuerte apoyo a la proposición de que los arreglos institucionales son, de hecho, una de las fuentes últimas de crecimiento a largo plazo, aunque muestran que no existe consenso sobre la persistencia de los marcos institucionales ni sobre la demora que un cambio institucional pueda tener para afectar a la situación económica. Por tanto, elegir un marco apropiado es una cuestión que aún permanece abierta.

«Mientras que la teoría es bastante precisa en términos de modelización de los determinantes económicos del crecimiento, es mucho menos instructiva en el modelado del papel de las instituciones [...] Como resultado, los estudios existentes se basan en diversas especificaciones ad hoc», señala Dawson (2003, p. 481, t. del a.).

\section{CONCLUSIONES}

Si bien cada día parece más aceptado que las instituciones son vitales para el crecimiento y el desarrollo económico, pocos trabajos han abordado esta problemática desde una perspectiva empírica y de largo plazo, particularmente para el caso argentino; y los trabajos existentes se han basado en índices parciales o que se concentran en variables relacionadas únicamente con políticas económicas.

Este artículo pretende generar un indicador que permita determinar si en Argentina existe alguna relación que vincule los períodos de crecimiento y estancamiento con la cuestión institucional. El indicador construido, de carácter multidimensional, constituye un avance en cuanto a la disponibilidad de herramientas de este tipo.

Los resultados sugirieren que la mala calidad institucional en Argentina no solo se habría reflejado en bajas tasas de crecimiento, sino en una menor capacidad de seguir a los países que evidenciaron un mejor desempeño. El deterioro institucional parece acompañar a la pérdida de puestos relativos experimentada por Argentina a partir de 1930, acentuada durante las décadas de 1950 y 1960 y profundizada alrededor de 1976. Particularmente dramático es el período 19501973, cuando el mundo crecía a tasas elevadas y Argentina lo hacía lentamente.

La historia argentina muestra, de manera sistemática, períodos de crecimiento interrumpidos por crisis y caídas del producto, seguidas luego por fases de recuperación. No son pocos los estudiosos que señalan al marco institucional como responsable de este patrón, y desde la perspectiva adoptada en este artículo parece confirmarse esa hipótesis. 
La recomendación sería que, para superar estos vaivenes, Argentina necesita el establecimiento de instituciones de alta calidad que protejan los derechos de propiedad y mantengan la estabilidad macroeconómica y social. Tener un sistema que genere políticas de calidad, estables y creíbles en el que los individuos puedan decidir teniendo en cuenta cuáles van a ser las políticas futuras y si estas respetarán sus derechos de propiedad no debería ser una alternativa de elección para Argentina sino un objetivo que hay que conquistar.

«La buena noticia es que los países no necesitan realizar grandes reformas para comenzar a crecer, pero sí para que ese crecimiento sea sostenido. Sin embargo, una vez que se han establecido instituciones sólidas, es mucho más sencillo mantener un círculo virtuoso en el que el crecimiento y la transformación institucional se retroalimenten» (Rodrik 2007, p. 191, t. del a.).

\section{BIBLIOGRAFÍA}

Acemoglu, D.; Johnson, S. y Robinson, J. (2001): "Colonial origins of comparative development: an empirical investigation». American Economic Review 91 (5), pp. 1.369-1.401.

Acemoglu, D.; Johnson, S. y Robinson, J. (2002): «Reversal of Fortune: Geography and Institutions in the Making of the Modern World Income Distribution». The Quarterly Journal of Economics 117 (4), pp. 1.231-1.294.

Acemoglu, D.; Johnson, S. y ROBINSON, J. (2004): "Institutions as the fundamental cause of long-run growth». NBER Working Paper 10.481, pp. 1-111.

Acemoglu, D. y Johnson, S. (2005): «Unbundling Institutions». Journal of Political Economy 113 (5), pp. 949-995.

Acemoglu, D.; Johnson, S.; Robinson, J. y Thaicharoen, Y. (2003): «Institutional Causes, Macroeconomic Symptoms: Volatility, Crises and Growth». Journal of Monetary Economics 50, pp. 49-123.

Acemoglu, D. y Robinson, J. (2008): «The Role of Institutions in Growth and Development». Working Paper Commission on Growth and Development World Bank 10, pp. 1-30.

Ades, A. y Di Tella, R. (1999): «Rents, Competition and Corruption». American Economic Review 89 (4), pp. 982-993.

Alesina, A.; Hausmann, R.; Hommes, R. y Stein, E. (1999): «Budget Institutions and Fiscal Performance in Latin America». Journal of Development Economics 59 (2), pp. 253-273.

Alesina, A. y Summers, L. (1993): "Central Bank Independence and Macroeconomic Performance: Some Comparative Evidence». Journal of Money, Credit, and Banking 25 (2), pp. 151-162.

Araoz, M. F. (2011): "La calidad institucional en Argentina en el largo plazo». Working Papers in Economic History (Universidad Carlos III de Madrid. 
Departamento de Historia Económica e Instituciones Instituto Figuerola de Historia y Ciencias Sociales) 11-11, pp. 1-40.

ARndt, C. y OMan, C. (2006): Uses and Abuses of Governance Indicators. París: OECD Development Centre Studies.

Barro, R. J. (1999): "Determinants of Democracy». Journal of Political Economy 107 (S6), pp. 158-183.

Bluhm, R. y SzIRmaI, A. (2012): «Institutions and long run growth performance: An analytic literature review of the institutional determinants of economic growth». Working Paper Series on Institutions and Economic Growth: IPD WP02 2012-2033.

Chang, H. J. (2010): "Institutions and Economic Development: Theory, Policy and History». Journal of Institutional Economics 7 (4), pp. 473-498.

Bidegain, Carlos M. (1995): Curso de Derecho Constitucional, tomo III. Buenos Aires: Abeledo Perrot. Constitución de la Nación Argentina.

Texto de la Constitución de 1853 con las reformas de 1860, 1866, 1898 y 1957.

Texto original de la Constitución Argentina de 1853. Texto de la Constitución de 1949.

Texto Ordenado la Constitución de 1994 (Ley n² 24.430).

Estatuto Fundamental de 1972.

CoRtés Conde, R. (1997): La economía argentina en el largo plazo (siglos XIX y $X X)$. Buenos Aires: Editorial Sudamericana.

Cortés Conde, R. (1998): Progreso y declinación de la economía argentina. Buenos Aires: Fondo de Cultura Económica.

Cortés Conde, R. (2005): La economía política de la Argentina en el siglo XX. Buenos Aires: Edhasa.

Cukierman, A. (1992): Central Bank Strategy, Credibility, and Independence: Theory and Evidence. Cambridge: The MIT Press.

Cukierman A., Webb, S. y Neyapti B. (1992): "Measuring the Independence of Central Banks and its effect on Policy Outcomes». The World Bank Economic Review, 6 (3), pp. 353-398.

Dawson, J. W. (2003): "Causality in the freedom-growth relationship». European Journal of Political Economy 19 (3), pp. 479-495.

Della Paolera, G. y Taylor, A. (1998): «Economic recovery from the Argentina Great Depression: institutions, expectations and the change of macroeconomic regime». Journal of Economic History 59 (3), pp. 567-599.

ENGERman, S. L. y SoKOlofF, K. L. (2002): «Factor Endowments, Inequality, and Paths of Development among the New World Economies». NBER Working Paper 9.259, pp. 1-55.

Engerman, S. L. y Sokoloff, K. L. (2005): "Colonialism, inequality, and longrun paths of development». NBER working paper 11.057, pp. 1-34.

Estévez García, J. F. y PÉrez García, M. J. (2007): Sistema de indicadores para el diagnóstico y seguimiento de la Educación Superior en México. México: ANUIES. 
Gallo, A. y Alston, L. (2008): «Argentina's Abandonment of the Rule of Law and Its Aftermath». Washington University Journal of Law \& Policy 26, pp. 153-182.

Glaeser, E.; La Porta, R.; Lopez-De-Silanes, F. y Shleifer, A. (2004): "Do Institutions Cause Growth?», Journal of Economic Growth 9, pp. 271-303.

Gerchunoff, P. y Llach, L. (2005): El ciclo de la ilusión y el desencanto. Buenos Aires: Ariel ( $2^{\mathrm{a}}$ ed.).

Hofman, A. (2001): Long run economic development in Latin America in a comparative perspective: proximate and ultimate causes. Santiago, Chile: United Nations Publications, Macroeconomics of Development series.

KaUfMANN, D. y KraAY, A. (2008): "Governance Indicators: Where are we, where should we be going?». The World Bank Research Observer 23 (1), pp. 1-30.

La Porta, R.; Lopez De Silanes, F. y Shleifer, A. (1998): «The Quality of Government». Journal of Law, Economics and Organization 15 (1), pp. 222-279.

Llach, J. (1987): Reconstrucción o estancamiento. Buenos Aires: Tesis.

Molinelli, N. G.; Palanza, V. y Sin, G. (1999): Congreso, Presidencia y Justicia en Argentina. Buenos Aires: Temas.

North, D. (1990): Institutions, institutional change and economic performance. Cambridge: Cambridge University Press.

Pizarroso Quintero, A.; Aguilera, C. y Aguilera Castillo, C. (1994): Historia de la prensa. Madrid: Ramón Areces.

Prados De La Escosura, L. y Sanz-Villarroya, I. (2009): «Contract enforcement, capital accumulation, and Argentina's long-run decline». Cliometrica 3 (1), pp. 1-26.

Przeworski, A. (2004): «The last instance: are Institutions the primary cause of growth?». European Journal of Sociology 45 (2), pp. 165-188.

Raimund, C. y Tilli, M. (1996): Coparticipación. Hacia el Nuevo Contrato Social. Buenos Aires: Corregidor.

Rodrik, D. (2007): One Economics, Many Recipes. Princeton: Princeton University Press.

SANGuinetTi, J. (2002): «Determinantes políticos e institucionales ligados al desempeño fiscal: El caso de las provincias argentinas». Documento $n^{\circ} 75$, Centro de Estudios para el Desarrollo Institucional/Fundación Gobierno y Sociedad, pp. 1-32.

Sanz Villarroya, I. (2009): "Macroeconomic Outcomes and the Relative Position of Argentina's Economy, 1875-2000». Journal of Latin American Studies 41 (2), pp. 309-346.

SpILler, P. y Tommassi, M. (2000): «Los determinantes institucionales del desarrollo argentino: una aproximación desde la Nueva Economía Institucional». Documento $n^{\circ} 33$, CEDI. 
Sturzenegger, F. (2003): La Economía de los Argentinos. Buenos Aires, Argentina: Editorial Planeta.

TAYLOR, A. (1994): «Tres fases del crecimiento económico argentino». Revista de Historia Económica. Año 12, n 3, pp. 649-683.

Voigt, S. (2009): «How (not) to measure Institutions». Joint Discussion Paper

Series in Economics (by the Universities of Aachen - Gießen - Göttingen Kassel - Marburg - Siegen) 37, pp. 1-26.

Vítolo, A. (2007): Emergencias constitucionales III. Intervención Federal.

Buenos Aires: Ciudad Argentina.

\section{APÉNDICE: DESCRIPCIÓN METODOLÓGICA DE LA CONSTRUCCIÓN DEL ÍNDICE MEDIANTE ACP}

En esta sección, se presenta una breve descripción metodológica del proceso de construcción del Índice utilizando la metodología del ACP. Esta técnica de análisis multivariado permite simplificar un conjunto de datos reduciendo el número de variables, ya sea porque su exceso dificulta el análisis, o bien porque representan información redundante. Para ello, analiza las interrelaciones entre dichas variables y obtiene tantos componentes como variables analiza. Cada componente es una combinación lineal de las variables originales y es independiente y no correlacionado con los restantes componentes.

Veamos el Cuadro A.1. La columna 1 representa la información inicial de cada variable, que siempre es la unidad. La columna 2 muestra la cantidad de información que permanece en cada variable original, una vez que se han desechado algunos factores, por lo que permite tener una idea de la calidad de representación de las variables originales en los factores retenidos en el análisis. En definitiva, el Cuadro A.1permite concluir que todas las variables se explican bien mediante la estructura factorial, pues las comunalidades tras la extracción son elevadas.

No hay una regla definida respecto al número de componentes que hay que retener, aunque el criterio de Kaiser especifica la retención de todo componente con un autovalor mayor que 1. En nuestro caso, el número de componentes retenidos es 3 y, en conjunto, explican el $75,753 \%$ de la varianza del modelo. Esto se obtiene del Cuadro A.2, en el que se observan los autovalores y el porcentaje de varianza explicada por cada uno de los componentes.

La columna 1 de este cuadro indica la parte de la varianza de las variables inicialmente consideradas que explica cada componente y, por tanto, se tendrán tantos autovalores como variables se consideren. En el caso de los tres primeros componentes, este valor es superior a 1, lo que significa que cada uno de ellos explicaría la varianza de más de una variable. La columna 2 muestra el porcentaje de la varianza de todas las variables introducidas 
CUADRO A.1

COMUNALIDADES

\begin{tabular}{|l|c|c|}
\hline & Inicial (1) & Extracción (2) \\
\hline Democracia & 1,00 & 0,838 \\
\hline Justicia & 1,00 & 0,834 \\
\hline Presupuesto & 1,00 & 0,801 \\
\hline IF & 1,00 & 0,825 \\
\hline ES & 1,00 & 0,865 \\
\hline Independencia del BCRA & 1,00 & 0,662 \\
\hline Libertad de prensa & 1,00 & 0,502 \\
\hline CN & 1,00 & 0,684 \\
\hline CP & 1,00 & 0,762 \\
\hline Coparticipación & 1,00 & 0,801 \\
\hline
\end{tabular}

inicialmente que es explicado por cada componente. De modo coherente con lo señalado por los autovalores, alcanza su máximo valor en los tres primeros componentes: el primero explica el 39,617\% de la varianza total del modelo y el tercero el 12,793\%. La columna 3 muestra cómo se incrementa el porcentaje acumulado de varianza explicada conforme se suman los porcentajes de varianza explicada por cada componente.

La matriz de componentes (Cuadro A.3) permite relacionar las variables iniciales con los factores retenidos e indica las cargas de cada variable en cada uno de los componentes. Cuanta más alta sea la carga, más estrecha será la relación entre ambos, pues representa, en definitiva, la correlación entre el factor y las variables originales.

La matriz de componentes rotados (Cuadro A.4), por su parte, ofrece información que permite una mayor discriminación en el momento de agrupar variables, dado que la rotación hace que aquellas fuertemente correlacionadas entre sí presenten pesos factoriales elevados -en valores absolutos- L La rotación ayuda a mejorar la interpretación de la solución factorial, pues con este mecanismo se consigue que cada variable no sature en más de un factor.

Del Cuadro A.4 surge que el "Componente 1", con un 39,617\% de la varianza total explicada, se correlaciona positivamente con las variables «justicia», «libertad de prensa», «coparticipación» e «independencia del banco central» y negativamente con "presupuesto». Dada la naturaleza de las variables agrupadas, podríamos pensar en este componente como un subíndice de «derechos de propiedad». 
CUADRO A.2

VARIANZA TOTAL EXPLICADA

\begin{tabular}{|l|c|c|c|c|c|c|c|c|c|}
\hline \multirow{2}{*}{ Componente } & \multicolumn{4}{|c|}{ Autovalores iniciales } & \multicolumn{3}{|c|}{$\begin{array}{c}\text { Extracción de las sumas de cargas } \\
\text { al cuadrado (*) }\end{array}$} & \multicolumn{3}{c|}{$\begin{array}{c}\text { Rotación de las sumas de cargas al } \\
\text { cuadrado (*) }\end{array}$} \\
\cline { 2 - 10 } & Total (1) & \% Varianza (2) & \% Acumulado (3) & Total & \% Varianza & \% Acumulado & Total & $\%$ Varianza & \% Acumulado \\
\hline 1 & 3,962 & 39,617 & 39,617 & 3,962 & 39,617 & 39,617 & 3,466 & 34,659 & 34,659 \\
\hline 2 & 2,334 & 23,342 & 62,960 & 2,334 & 23,342 & 62,960 & 2,733 & 27,334 & 61,993 \\
\hline 3 & 1,279 & 12,793 & 75,753 & 1,279 & 12,793 & 75,753 & 1,376 & 13,759 & 75,753 \\
\hline 4 & 0,703 & 7,034 & 82,787 & & & & & & \\
\hline 5 & 0,579 & 5,793 & 88,580 & & & & & & \\
\hline 6 & 0,449 & 4,490 & 93,070 & & & & & & \\
\hline 7 & 0,249 & 2,489 & 95,559 & & & & & & \\
\hline 8 & 0,203 & 2,034 & 97,593 & & & & & & \\
\hline 9 & 0,138 & 1,377 & 98,970 & & & & & & \\
\hline 10 & 0,103 & 1,030 & 100,000 & & & & & & \\
\hline
\end{tabular}

(*) Hacen referencia a los porcentajes de varianza explicada tras la retención de los componentes. De ahí que únicamente se muestren los datos correspondientes a los tres primeros componentes. 
CUADRO A.3

MATRIZ DE COMPONENTES

\begin{tabular}{|l|c|c|c|}
\hline \multirow{2}{*}{} & \multicolumn{3}{|c|}{ Componente } \\
\cline { 2 - 4 } & $\mathbf{1}$ & $\mathbf{2}$ & $\mathbf{3}$ \\
\hline Justicia & 0,858 & $-0,310$ & 0,051 \\
Independencia del BC & 0,785 & $-0,207$ & $-0,053$ \\
Libertad de prensa & 0,707 & 0,015 & $-0,049$ \\
Coparticipación & 0,704 & $-0,525$ & $-0,173$ \\
Presupuesto & $-0,697$ & 0,553 & 0,094 \\
ES & 0,663 & 0,640 & $-0,131$ \\
Democracia & 0,303 & 0,860 & $-0,089$ \\
IF & 0,634 & 0,649 & $-0,051$ \\
CP & 0,081 & $-0,086$ & 0,865 \\
CN & 0,436 & 0,193 & 0,676 \\
\hline
\end{tabular}

Método de Extracción: Análisis de Componentes Principales; 3 componentes extraídos

El "Componente 2" explica el 23,342\% de la varianza total explicada y agrupa a las variables "democracia», "estado de sitio» e "intervenciones federales», variables relacionadas con la estabilidad política.

En tanto que el "Componente 3", con un 12,793\% de la varianza total explicada, concentra a las variables «cambios en la Constitución nacional» y «en las Constituciones provinciales», vinculadas con el Estado de derecho.

Estos tres componentes podrían admitirse como índices en sí mismos — de derechos de propiedad, estabilidad política y Estado de derecho-. No obstante, a fin de construir el indicador final, se estimó una combinación lineal de los mismos, ponderando por su porcentaje de varianza explicada ${ }^{40}$. Es decir:

$$
\begin{aligned}
& \text { Índice de Calidad Institucional }=\text { Componente } 1 \times 0,39617 \\
& + \text { Componente } 2 \times 0,23342+\text { Componente } 3 \times 0,12793
\end{aligned}
$$

Tal como se reseñó en el subapartado 3.2, el último paso fue normalizar los valores del indicador. Sus resultados se muestran en el Gráfico 1 del trabajo.

40 Metodología empleada para la construcción de indicadores de calidad institucional en instituciones educativas (Estévez García y Pérez García 2007, pp. 73-80). 
CUADRO A.4

MATRIZ DE COMPONENTES ROTADOS

\begin{tabular}{|l|r|r|r|}
\hline \multirow{2}{*}{} & \multicolumn{3}{|c|}{ Componente } \\
\cline { 2 - 4 } & $\mathbf{1}$ & $\mathbf{2}$ & $\mathbf{3}$ \\
\hline Coparticipación & 0,890 & & \\
Presupuesto & $-0,888$ & & \\
Justicia & 0,876 & & \\
Independencia del BC & 0,776 & & \\
Libertad de prensa & 0,594 & & \\
ES & & 0,898 & \\
Democracia & & 0,897 & 0,861 \\
IF & & 0,881 & 0,753 \\
CP & & & \\
CN & & & \\
\hline
\end{tabular}

Método de Rotación: Varimax con normalización de Kaiser. Método de Extracción: Análisis de Componentes Principales.

Nota: para facilitar la apreciación de estas relaciones y ayudar a la interpretación de los componentes, se ordenaron los coeficientes por su magnitud absoluta y se omitieron aquellos no mayores que 0,5 en valores absolutos. 